\title{
An Overview on Basics of Organic and Dyes Sensitized Solar Cells, Their Mechanism and Recent Improvement
}

\author{
Priyanka P. Kumavat ${ }^{a}$, Prashant Sonar ${ }^{b^{*}}$, Dipak S. Dalal ${ }^{a *}$
}

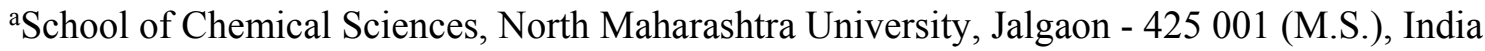

${ }^{b}$ Institute of Future Environment and School of Chemistry, Physics and Mechanical Engineering,

Queensland University of Technology (QUT) 4001 Brisbane, Australia

\section{Graphical Abstract}

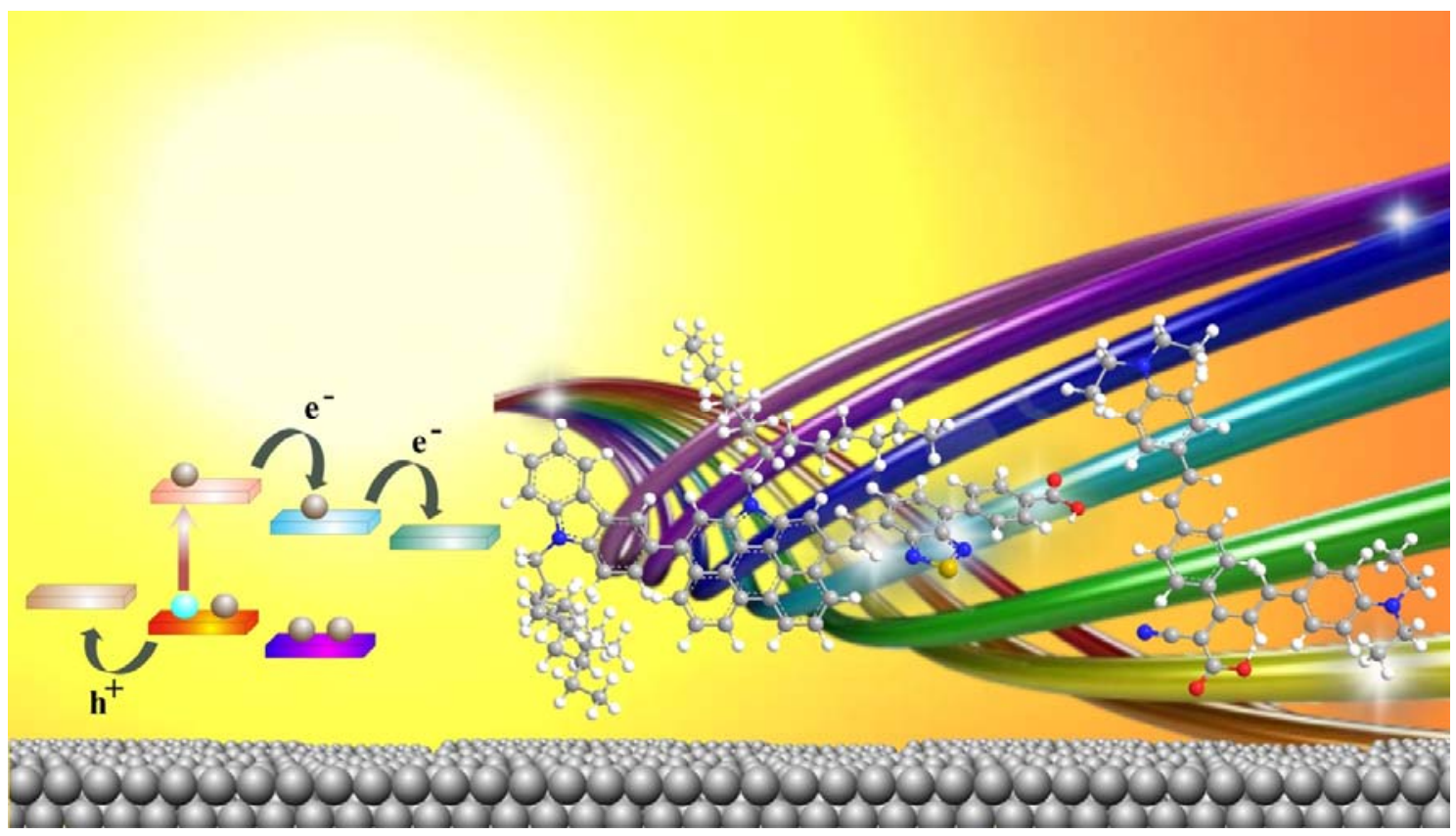




\begin{abstract}
Organic and dye sensitized solar cell devices have attracted a significant attention during last few years in scientific community due to their advantages such as low cost, easy processibility, large scale manufacturing and efficient conversion of solar energy into electrical energy. The main aim of this review is to provide torchlight for organic chemist willing to start exploration in the field of solar cell as it includes an overview of organic and dye sensitized solar cells. This review covers detailed history for development of solar cell, some basic terminologies used in organic and dye sensitized solar cells. The review article gives attention toward synthetic utility of organic molecules towards different types of solar cell such as single layer, double layer and bulk heterojunction solar cells, their mechanisms and type of materials which are generally used for solar cell device fabrication. The review specially gives focus on the up to date information about improvements in Organic Solar Cells (OSCs) and Dye Sensitized Solar Cells (DSSCs) which will be a handy tool for young budding researchers to explore the molecular engineering opportunities in terms of designing and synthesizing more efficient exotic materials for solar cell.
\end{abstract}

Keywords: Organic Solar cell, Dye sensitized Solar cell, Efficiency, Metal Oxide Semiconductors. 


\section{Contents}

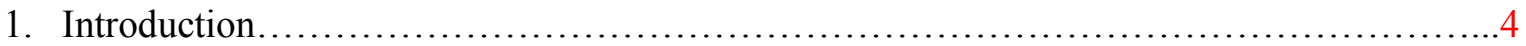

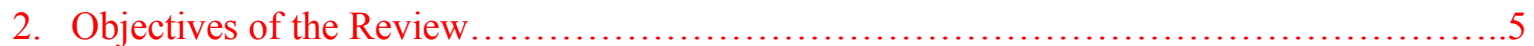

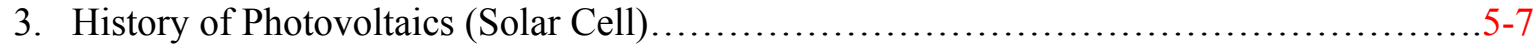

4. Conventional Solar Cell and Organic Heterojunction Solar cells........................ $7-10$

3.1 Single Layered Solar Cell

3.2 Bilayer Structured Cells

3.3 Bulk Heterojunction Device

5. Comparison of Organic Solar Cells and Inorganic Solar Cells....................... 10-11

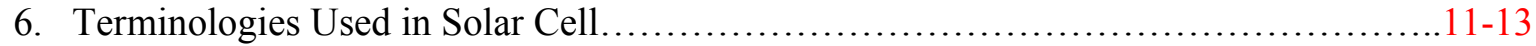

7. Mathematical modelling............................................................. 18

7.1 1D pseudo-bilayer Device

7.2 3D pseudo-bilayer Device

8. Metal Oxide Semiconductors................................................ 18-20

9. Improvements in OSCs and DSSCs.............................................. $20-54$

10. Recent Improvements in Electrolytes Used in Solar Cell...........................54-57

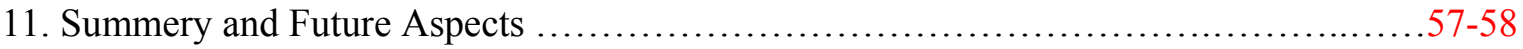

Acknowledgement

References

\section{CORRESPONDING AUTHOR FOOTNOTE}

Dr. Dipak S. Dalal

Tel: +91- (257) 2257432 E-mail: dsdalal2007@gmail.com

Dr. Prashant Sonar

Tel: +61 731381945 E-mail: sonar. prashant@qut.edu.au 


\section{Introduction}

Over the past decade, the thrust for renewable energies have came in limelight due to the world's ever increasing demand for energy [1]. Different forms of renewable energies like biomass, wind, hydroelectric, marine tidal, geothermal and solar energy are recognized as alternatives for traditional sources [2]. Among these renewable energies, solar energy is a key technology obtained from sunlight which includes utilization of sun energy in different manner. Sunlight is inexpensive, non-polluting, abundant, unique natural resource of clean energy [3]. Earth receives $1.75 \times 10^{17} \mathrm{~W}$ of energy from the sun which is enough to satisfy the annual energy demand of world in less than hour. This fascinating fact of sunlight is pinching researcher worldwide regarding its utilization for mankind and the main man made interface which converts sunlight energy into the electrical energy. The commercially existing solar cells are currently based on the inorganic silicon semiconductors which will result proliferation in of silicon demand in next decade and price of silicon will rise dramatically [4]. Due to this, Organic Solar Cells (OSCs) also known as Organic Photovoltaics or OPVs has gained considerable attention from industry and researchers in recent past. Use of OSCs in place of conventional inorganic semiconductors plays vital role due to their easy synthesis, low manufacturing costs, large area coverage and flexible surface [5]. Additionally, attraction towards OSCs was due to easy modulation in optical band gap and energy levels with respect to various conjugated building blocks, compatibility with other deposition technologies for device fabrication [6]. For an efficient OSCs following five processes are important:

1. Light absorption followed by excitons generation

2. Excitons diffusion towards active interface

3. Then charge should be dissociated and separate

4. Separated charge should be easily transport

5. Collection of charge 


\section{Objectives of the Review}

Based on above mentioned principle steps, many researchers worldwide researching different types of conjugated organic donor and acceptor materials including small molecules and polymers to produce world class highly efficient organic photovoltaic devices. For the advancement of mankind, in recent years, worldwide thrust for newer, efficient, safer and greener energy sources has been increased tremendously. Moreover, sun light is the most reliable and affordable energy source for our planet. If we learn to harvest maximum energy provided by sunlight, we can bring lot of ecological, environmental and energy efficient technological benefits to the mankind to the level which were never achieved before. This is a a great need for the society and therefore, scientists are focusing how to tap the energy from sunlight in a more cheaper and safe way. In this review, we have tried to focus on some the recent advances taking place in OSCs and DSSCs research field with some fundamental knowledge using basic terminologies. Knowledge of historic development of OSCs and DSSCs technology along with current happenings in this domian will be helpful to the solar cell research community for their strateigeis and future work plan. Also, this review complies some basics of OSCs and DSSCs, their mechanism, type of materials involved, molecular engineeriging aspects attributed with various properties and recent cutting edgre research happeneing in this field. Main objective this review is to be a pathfinder for young growing communities and early stage researcheres who wants to explore energy harvesting materials and devices for future work.

\section{History of Photovoltaics (Solar Cell)}

"The beginning" of the solar cell technology is the discovery of photovoltaic effect by a French physicist Alexandre-Edmond Becquerel in 1839. He used two electrodes coated with $\mathrm{AgCl}$ or $\mathrm{AgBr}$ as light sensitive materials and kept in a black box surrounding in acid solution. The increased electricity was observed after exposing it to the light. Then it took 
1873 when Willoughby Smith discovered selenium photo conductivity followed by William Grylls Adams and Richard Evans Day discovery in 1876 that selenium harvests electrical current on exposing with sun light. But drawback of this was created solar cell was very inefficient and energy created by this was not sufficient to run any electrical apparatus. In 1893, Charles Fritts introduced the first solar cell from selenium wafer. Then in 1894, Charles Fritts coated a selenium with thin layer of gold and used as a light sensor, not as energy supply due to the low efficiency of about $1 \%$. After this pioneer research in $18^{\text {th }}$ centuary, German physicist Wilhelm Ludwig Franz Hallwachs in 1904 observed photosensitivity by combination of copper and cuprous oxide. Albert Einstein in 1905 discovered how exactly light caused photoelectric effect-essentially, photovoltaics. He stated that light travels as energy packets, he called them photons and energy fluctuates only with its frequency. This revolutionary theory gave well explaination to photon absorption with regards to light frequency. This theory was followed by Nobel Prize winning research by Robert Millikan in 1916. He worked on the photoelectric effect and measured charge of the electrons. Then Polish chemist Jan Czochralski reported a growth of single-crystal silicon which shows efficiency increament for silicon-based cells. Bell Labs produced solar cells in 1950 which can be utilised for space activities by discovering a silicon solar cell and this was the first cell which can run electrical devices using sunlight. This fascinating discovery by Bell Labs was resulted in the launch of Telstar communications satellite powered (14W) by solar cells in 1962. Simultaneouly, cadmium sulphide p-n junction was reported with $6 \%$ efficiency in 1954 and in 1960, Hoffman Electronics came up with a solar cell having 14\% efficiency. The world's first photovoltaic research and development laboratory 'The Institute of Energy Conversion', University of Delaware is established in 1972 with primary objective of research and development on thin-film photovoltaic and solar thermal systems. Then in 1972, David Carlson and Christopher Wronski, RCA Laboratories prepared first amorphous silicon 
photovoltaic cells with $1.1 \%$ efficiency. University of Delaware in 1980 developed copper sulphide and cadmium sulphide thin-film solar cell which exceeds $10 \%$ efficiency. In 1981 , Paul Macready made aircraft assembled with 1600 cells on its wings which produced a power of $3 \mathrm{~kW}$ and this aircraft flew from France to England. In 1989, solar cells using reflective solar concentrators were reported. In 1992, University of South Florida made of cadmium telluride thin-film photovoltaic cell with $15.9 \%$ efficiency. The first solar cell to exceed $30 \%$ conversion efficiency was reported by National Renewable Energy Laboratory in 1994 using gallium indium phosphide and gallium arsenide which was again crossed as $32.3 \%$ in 1999 . Recently in 2007, university of Delaware achieved a $42.8 \%$ world record power conversion efficiency in solar cell technology. Since past few years, there has seen a huge investment in utility-scale solar plants and the efficiency record break is getting common due to advancement in sciences and critical mass working on these technologies. In 2012, "Golmud Solar Park" is in China came up with the largest solar energy plant with an installed capacity of 200 megawatts. This is perhaps exceeded by India's “Gujarat Solar Park" scattered around the Gujarat region in the form of solar farms, with installed capacity of 605 megawatts.

\section{Conventional Solar Cell and Organic Heterojunction Solar Cells}

Conventional solar cells are based on the minority carrier diffusion process which creates the photovoltaic current. At p-n junction, a bunch of electrons move to the $\mathrm{p}$-side, creating the built-in voltage. This electric field makes it easy for electrons to move from $\mathrm{p}$ to $\mathrm{n}$, but impossible the other way around. A photon with enough energy will excite an electron from the $\mathrm{p}$ side to the $\mathrm{n}$ side causing interruption of electrical balance. Then application of external current drive electrons to the $\mathrm{p}$ side to which will then combine holes sent by electric field. This electron flow genearte the current and the cell's electric field produces a voltage. This resulted current and voltage will give power. 
However, use of two or more layers of different materials with different band gaps shows efficiency increment. Loading higher band gap material on the surface to absorb high-energy photons can result better efficiencies and this approach is used in multi-junction cells. The anode cannot be too large or it will block the incoming light. If it is too small, then it will not conduct well. A grid of some type is usually used. Additionally, an anti-reflective coating must be applied along with a glass cover to protect the cells. Organic solar cells involve majority charge carriers since holes are located in the highly occupied molecular orbital (HOMO) of donor phase and electrons are present in the lowest unoccupied molecular orbital (LUMO) of acceptor phase and their movements result in photovoltaic current. Organic solar cells made up from blends of conjugated polymers or conjugated organic compounds (donor) and fullerenes (acceptor). Upon absoprtion of photon or light, the active layer made of donor and acceptor mixed morphology creates electron-hole bounded pair called as an exciton. Exciton diffusion lengths are quite small and exctions can only travel till 10-20 nm distance. Upon reaching exciton at the interface of donor-acceptor present in the active layet, it gets disccosited into the free charges such as holes and electrons. The nanomorphology of the active layer blend plays a vital role to assist exciton diffusion and exction dissociation into free charges.so the active layer morphology engineering is extreemly important.

(a)

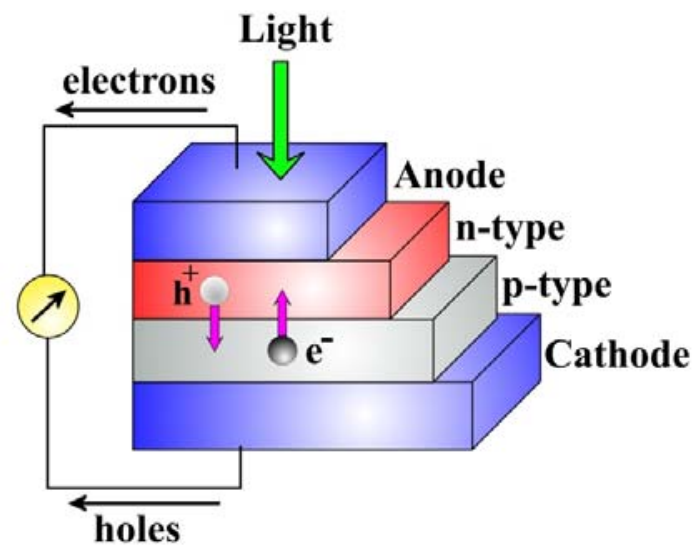

(b)

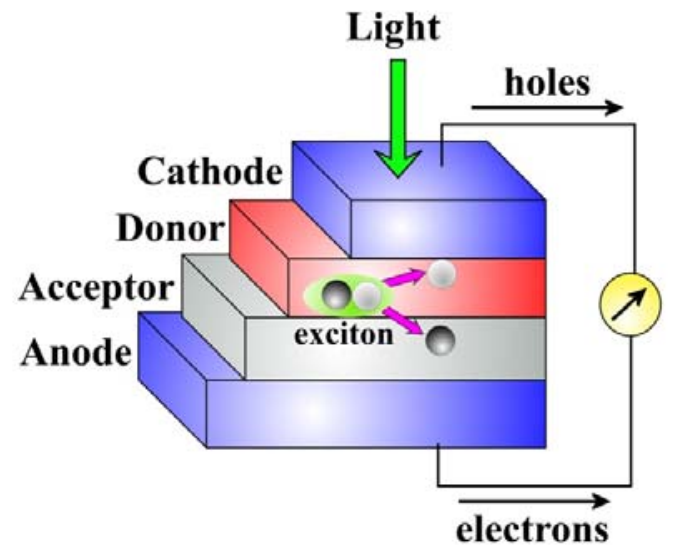

Fig.1. (a) Conventional Solar Cell (b) Organic Heterojunction Solar cell 
The active semiconducting materials used in organic or polymer solar cells is always carbon based organic compounds either in the form of small molecules, dendrimers or polymer which converts solar energy into electric energy. Such organic molecules with capability of light absorption induces the passage of electrical charges between donor conduction band to the acceptor conduction band of molecule. Such type of OSCs can be devided into three types as single layered, bilayer and bulk heterojuction (BHJ) structured cells.

\subsection{Single Layered Solar Cell}

The first generation of OSCs were mainly constructed by single organic layers [7-9] placed between two metal electrodes $[\mathbf{1 0 , 1 1}]$. The single layer structure has an intrinsic limitation in achieving high efficiency because the organic layer, where it is p-type or n-type, between electrodes cannot properly generate individual charges (holes and electrons) owing to the extremely low charge separation yield originated from the nature of tightly-bound excitons in organic semiconductors [12]. Recently, Kippelen B et al, reported single-layer OSCs with efficiencies up to $5.9 \pm 0.2 \%[13]$.

\subsection{Bilayer structured cells}

In a bilayer/multilayer OSCs, photoactive layers containing donor and acceptor organic materials absorb sunlight and generate photocurrents. The donor material (D) is usualy electron rich molecules which are capable of donating electrons which create holes whereas the acceptor material (A) should have capacity to accept electrons. This photoactive layes harvest photons from sunlight to form excitons. Excitons is the state of electrons in which it gets excited from the valence band into the conduction band. This creation of excitons in donor layer resulted in concentration gradient phenomenon and due to this, excitons start to diffuse towards donor/acceptor interface and then separates into free holes and electrons. As soon as this charge separation process takes place free holes and electrons moves to the corresponding electrodes and resulted in photovoltaic. In a bilayer heterojunction device, p- 
type and n-type materials are consecutively placed with each other [14]. Different combinations of materials used in bilayer devices using organic semiconductors were reported [15-21].

\subsection{Bulk Heterojunction Device}

The bulk heterojunction device [22-25] shows improved interfacial area where charge separation occurs as compared to bilayer device. Bulk heterojunction is prepared by bulk volume mixing of donor and acceptor components which results in very small exciton diffusion length at donor-acceptor interface [26]. In such type of devices, excitons are generated on photon absorption of organic materials. Then dissociation of excitons gives charge collection at corresponding electrodes and this process occurs at the heterojunction interface [27].
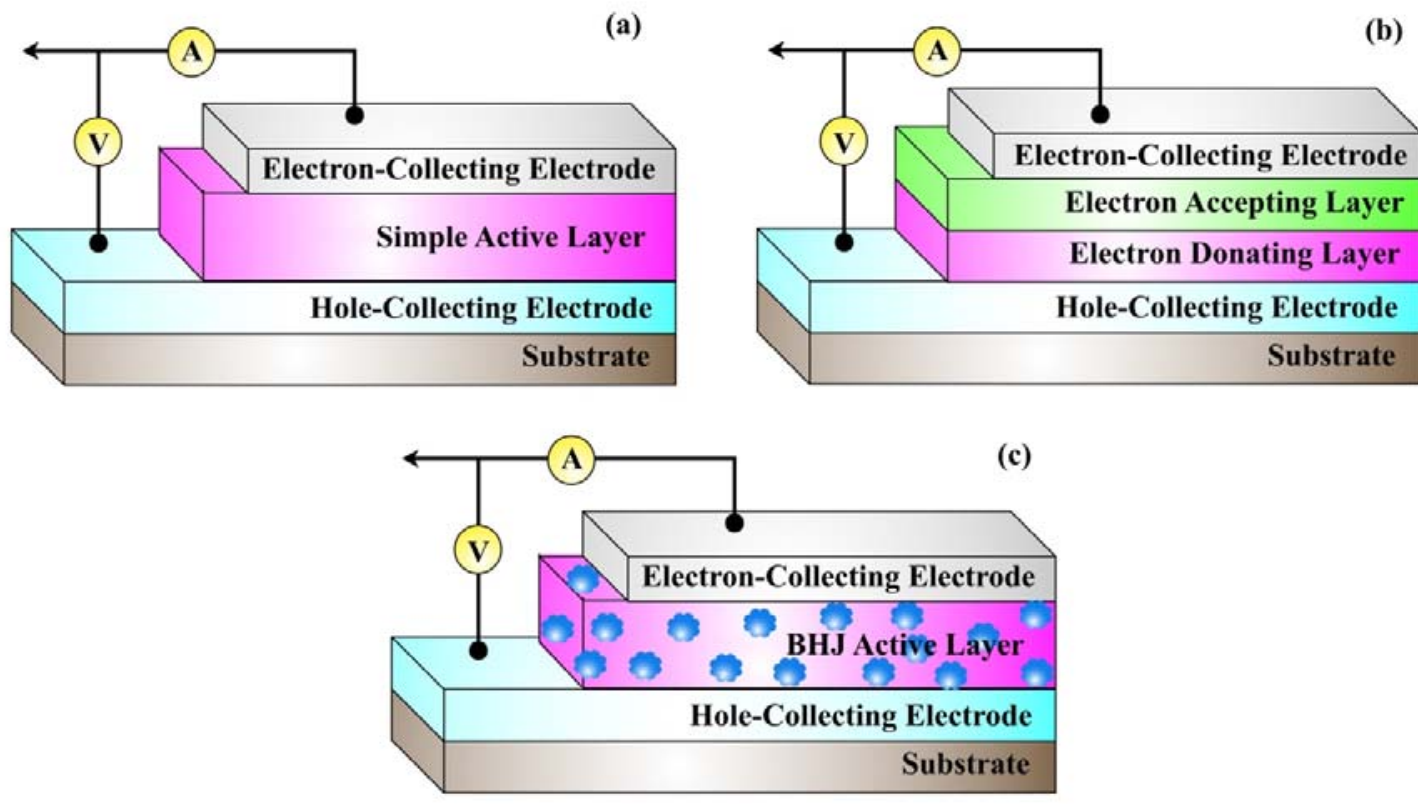

Fig 2. (a) Single layered solar cell (b) Bilayer structured cells (c) Bulk heterojunction device

\section{Comparison of Organic Solar Cells and Inorganic Solar Cells}

Inorganic semiconductors show good band gap energies in concern with solar spectrum. But the major drawback is they possesses lesser light absorptivity than organic materials. 
Therefore, inorganic semiconductors require more quantity of absorbing layers which makes them thicker. Also, to achieve better efficiency, purity of inorganic semiconductors is most important factor which increases cost with increase in purity. In both types exited state has been achieved after photon absorption. However, in inorganic semiconductors required binding energy for excitons (also known as exction bidning energy) to form charge carriers is quite small as compared to OSCs and simply attained at room temperature. Due to this reason, inorganic semiconductor devices are generally possessing high efficiency as compared to OSCs. On other hand, OSCs can require exciton binding energy as high as 0.5 $\mathrm{eV}$ or higher. This high exciton binding energy as compared to inorganic semiconductors is the consequence of a donor-acceptor heterojunction formation where exciton dissociation takes place and this process needs internal electrochemical driving force. In OSCs, combination of donor-acceptor is important with maximum interface area between them because formed excitons should reach the interface to disassociate as quickly as possible. At instant when formed excitons disassociate into two separated species i.e. electrons and holes (As shown in Fig. 1b), they must transfer proficiently in the direction of electrodes. So during fabrication of OSCs, we should aim toward easy mobility of electrons and holes which will ultimately results in better efficiency.

\section{Terminologies used in Solar Cell}

The most important terms that are widely used to determine the performance of solar cells are as follows;

\subsection{Air Mass (AM):}

The Air Mass is given as:

$$
\mathrm{AM}=1 / \cos (\theta)
$$

Where, $\theta$ is the vertical angle (zenith angle). When zenith angle is zero i.e. the sun is directly overhead, the value of Air Mass is eual to 1. 
The air mass coefficient is generally used to describe the standardized condition performance of solar cells. Its value is representated as 'AM1.5' where 1.5 is thickness of atmosphere with $48.2^{\circ}$ solar zenith angle. Generally, a standard spectrum and power density are used for accurate and precise comparison between performance of cells at different time and location. The terms 'AM 1.5G' (G stands for global) which includes direct as well as diffuse radiation or 'AM $1.5 \mathrm{D}$ ' which includes only direct radiation are used for standard spectrum at the Earth's surface.

\subsection{Open Circuit Voltage (Voc):}

Open circuit voltage is defined as the maximum voltage available from a solar cell when net current through the device zero. It is represented by symbol Voc. Usually theoretically open circuit voltage can be determined by taking the difference of HOMO of the donor component and LUMO of the acceptor component into account. This theoretical HOMO-LUMO difference can be corealted with the experimental obtained value via I-V characteristics.

\subsection{Short Circuit Current (Isc):}

This is the current when the terminals are connected to each other i.e zero load resistance. It increases with the intensity of light because higher intensity gives more photons and electrons. The short circuit current denoted by ISC is proportional to the area of the solar cell called short circuit current density symbolized by $\mathrm{J}_{\mathrm{sc}}=\mathrm{I}_{\mathrm{sc}} / \mathrm{A}$.

\subsection{Fill Factor (FF):}

In combination with Voc and Isc, it gives the vaue of maximum power generated by a solar cell and it is given by,

$$
\mathrm{FF}=\mathrm{P}_{\max }\left(\mathrm{mW} \cdot \mathrm{cm}^{-2}\right) / \mathrm{J}_{\mathrm{sc}}\left(\mathrm{mA} \cdot \mathrm{cm}^{-2}\right) \cdot \mathrm{V}_{\mathrm{OC}}(\mathrm{V})
$$

Where, $\mathrm{P}_{\max }$ is maximum power from the solar cell. 
Efficiency $\eta_{\text {cell }}$ can be determined by the ratio $P_{\max }$ to the total incident light power $\mathrm{P}_{\text {irr }}(1$ sun $=\mathrm{P}_{\text {irr }}=100 \mathrm{mWcm}^{-2}$ ) shown by the equation-

$$
\eta \%=\mathrm{P}_{\max } / \mathrm{P}_{\text {irr }} .100 \%
$$

Uusally fill factor of organic solar cell devices depends on the charge carrier mobility of hole and electrons arising from the donor and acceptor components. If the hole mobility and electron mobility is higher and in balance then solar cell devices gives higher FF.

\subsection{Internal Photon to Current Conversion Efficiency (IPCE):}

IPCE defines the usefulness of a solar cell in terms of conversion of incident photons of given wavelength into photocurrent and its value is .

$$
\begin{gathered}
\mathrm{IPCE}=\mathrm{J}_{\mathrm{SC}} \cdot \mathrm{hc} / \mathrm{P}_{\text {irr }} \text {. e. } \lambda \\
\mathrm{IPCE}=\left(1239.8 . \mathrm{J}_{\mathrm{SC}}\left(\mathrm{mA} \cdot \mathrm{cm}^{-2}\right) / \mathrm{P}_{\text {irr }}\left(\mathrm{mW} \cdot \mathrm{cm}^{-2}\right) \lambda(\mathrm{nm}) \cdot 100 \%\right)
\end{gathered}
$$

Where,

$\mathrm{c}=$ speed of light $\left(\mathrm{ms}^{-1}\right), \mathrm{J}_{\mathrm{SC}}=$ short- circuit photocurrent density $\left(\mathrm{Am}^{-2}\right), \mathrm{h}=$ Planck's constant $(\mathrm{Js}), \mathrm{P}_{\mathrm{ir}}=$ power of incident light $\left(\mathrm{Wm}^{-2}\right), \mathrm{e}=$ elementary charge $(\mathrm{C})$

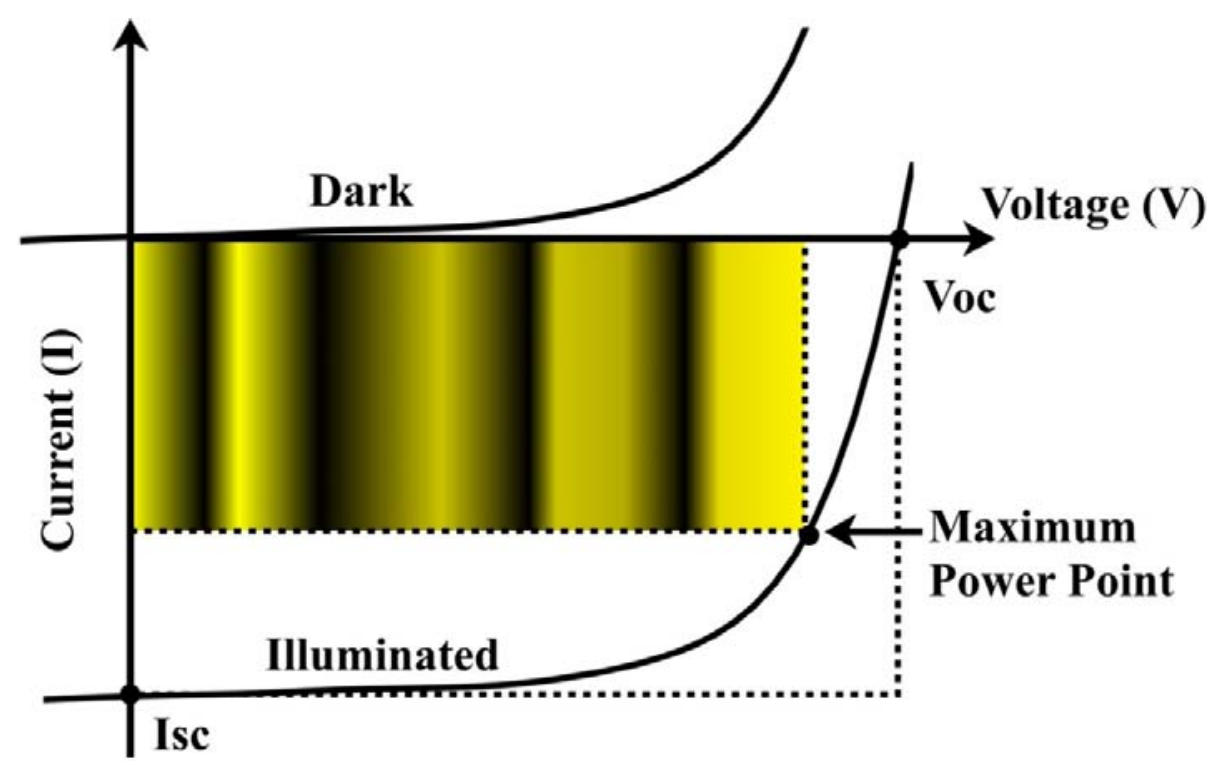

Fig 3. General representation of current- voltage response of solar cell 


\section{Mathematical modelling}

Fig 4. Representation for active layers of (a) Pseudo-bilayer solar cells (b) BHJ structure in which layer thicknesses of donor and acceptor ( $l_{d}$ and $l_{a}$ ) are reduced to zero (c) Bilayer structure in the limit of zero blend layer thickness, lb (The Roman numbers represents boundary conditions)

\subsection{D pseudo-bilayer device}

Firstly, for donor layer (Fig. 4a) where the conservation of holes and excitons takes place and Poisson equation can be solved as,

$$
\begin{gathered}
\nabla . J_{h}^{(d)}=0, \\
\nabla . J_{e x}^{(d)}=G_{e x}-\frac{n_{e x}}{T_{e x}}, \\
-\nabla^{2} \psi^{(d)}=\frac{e}{\varepsilon_{0} \varepsilon_{\delta}} n_{h}
\end{gathered}
$$

Where,

$J_{h}^{(d)}$ and $J_{e x}^{(d)}=$ Hole and Exciton fluxes in the donor layer, 
$G_{e x}=$ Exciton generation rate of donor,

$n_{e x}=$ Exciton concentration,

$T_{e x}=$ Exciton lifetime,

$\psi^{(d)}=$ Electric potential in the donor layer,

$e=$ Elemental charge,

$\varepsilon_{\delta}=$ Dielectric constant of donor,

$\varepsilon_{0}=$ Permittivity of free space,

$n_{h}=$ Hole concentration

Also for the acceptor layer (Fig. 4a) where conservation of electrons takes place and the Poisson equation can be solved as,

$$
\begin{gathered}
\nabla \cdot J_{e}^{(a)}=0, \\
-\nabla^{2} \psi^{(a)}=-\frac{e}{\varepsilon_{0} \varepsilon_{\alpha}} n_{e}
\end{gathered}
$$

where,

$J_{e}^{(a)}=$ Electron flux in the acceptor layer,

$n_{e}=$ Electron concentration,

$\varepsilon_{\alpha}=$ Dielectric constant of acceptor

Next case is for the blend layer, we can solve for conservation of electrons and holes coupled with the Poisson equation as,

$$
\begin{gathered}
\nabla . J_{e}^{(b)}=S, \\
\nabla . J_{h}^{(b)}=S, \\
-\nabla^{2} \psi^{(b)}=\frac{e}{\varepsilon_{0} \varepsilon}\left(n_{h}-n_{e}\right)
\end{gathered}
$$

where

$J_{e}^{(b)}$ and $J_{h}^{(b)}=$ Electron and hole fluxes in the blend layer, 
$S=$ Net charge generation rate,

$\varepsilon=$ Dielectric constant of the blend layer

Let's now consider boundary conditions.

First at the acceptor/current collector contact (see boundary I in Fig. 4a), the potential is without loss of generality set to be zero and the electron and hole concentrations are given by Boltzmann statistics,

$$
\psi=0, n_{e}=N_{c v}, n_{h}=N_{c v} \exp \left(\frac{-e V_{b}}{k_{B} T}\right)
$$

Where,

$N_{c \nu}=$ Effective density of states for electrons and holes,

$V_{b}=$ Built-in voltage of the cell,

$k_{B}=$ Boltzmann constant,

$\mathrm{T}=$ Temperature

At the donor/current collector contact (see boundary IV in Fig. 4a), the potential, charge concentrations and exciton concentration is given as,

$$
\psi=V_{a}-V_{b}, n_{e}=N_{c v} \exp \left(\frac{-e V_{b}}{k_{B} T}\right), n_{h}=N_{c v}, n_{e x}=0
$$

Where,

$V_{a}=$ Applied voltage

At the acceptor layer/blend layer interface (see boundary II in Fig. 4a), the electric potential and electron flux are assumed to be continuous, whereas holes are assumed to not move into the acceptor layer,

$$
\psi^{(a)}=\psi^{(b)},\left(J_{e}^{(a)}-J_{e}^{(b)}\right) \cdot e_{x}=J_{h}^{(b)} \cdot e_{x}=0
$$


At the blend layer/donor layer interface (see boundary III in Fig. 4a), the dissociation of excitons from donor layer pays to additional fluxes of electrons and holes; in addition, the electric potential and exciton concentration are given as,

$$
\left(J_{h}^{(d)}-J_{h}^{(b)}\right) \cdot e_{x}=-J_{e}^{(b)} \cdot e_{x}=-P J_{e x} \cdot e_{x}, \psi^{(b)}=\psi^{(d)}, n_{e x}=0
$$

Where,

$\mathrm{P}=$ Dissociation probability

Furthermore, trilayer structure of the organic pseudo-bilayer solar cell (Fig. 4a) can be reduced to the structure of a BHJ cell (Fig. 4b). In this limit, the mathematical model reduces to the conventional $1 \mathrm{D}$ as described above.

Alternatively, Fig. $4 \mathrm{c}$ represent the structure of bilayer solar cell where $\mathrm{h} \sim 1 \mathrm{~nm}$. In this limit, the mathematical model corresponds to a 1D, two-phase device model with the simplest D/A structure. However, one more set of boundary conditions is required as $\mathrm{l}_{\mathrm{b}}$ tends to $\mathrm{h}$ at the donor/acceptor interface,

$$
\begin{gathered}
J_{h}^{(d)} \cdot e_{x}=-J_{e}^{(a)} \cdot e_{x}=h\left[P g_{e / h}-(1-P) k_{r} n_{e} n_{h}\right], \\
\psi^{(a)}=\psi^{(d)}, n_{e x}=0
\end{gathered}
$$

where,

$g_{e / h}=$ Volumetric generation rate of interfacial $e / h$ pairs within $\mathrm{h}$ from the D/A and also given as,

$$
g_{e / h}=\frac{-J_{e x}^{(d)} \cdot e_{x}}{h}
$$

Substituting this value of $g_{e / h}$, we can write above equation as,

$$
J_{h}^{(d)} \cdot e_{x}=-J_{e}^{(a)} \cdot e_{x}=-P J_{e x} \cdot e_{x}-h(1-P) k_{r} n_{e} n_{h}
$$

\subsection{D pseudo-bilayer device}

Above mentioned Poisson equations for D/A layers are the simplest case of two-phase models with a 1D bilayer donor-acceptor structure. However, two-phase models could also 
incorporate general 3D bilayer donor-acceptor structures. The formulation for 3D two-phase models remains largely the same as the 1D formulation described above, with the exception of following two distinctions,

1. The boundary conditions at donor-acceptor interfaces should be rewritten to rewritten the random orientation of donor-acceptor interfaces in 3D morphologies,

$$
\begin{gathered}
J_{h} \cdot n_{\alpha \delta}=-J_{e} \cdot n_{\alpha \delta}=P J_{e x} \cdot n_{\alpha \delta}-h(1-P) k_{r} n_{e} n_{h}, \\
\psi_{\alpha}=\psi_{\delta}, \eta_{e x}=0
\end{gathered}
$$

Where,

$n_{\alpha \delta}=$ Unit normal vector pointing from acceptor phase to donor phase,

$\psi_{\alpha}$ and $\psi_{\delta}=$ Electric potential in acceptor phase and donor phase

2. Additional boundary conditions are required at the bounding surfaces in the $y$ - and z-directions, i.e. the non-contacted surfaces. These are assumed to be well-insulated, so that the following no-flux conditions apply,

$$
\begin{gathered}
e_{y(z)} \cdot J_{h}=e_{y(z)} \cdot J_{e}=e_{y(z)} \cdot J_{e x}=0 \\
e_{y(z)} \cdot \nabla \psi_{\alpha}=e_{y(z)} \cdot \nabla \psi_{\delta}=0
\end{gathered}
$$

This mathematical formulation for 3D two-phase model serves as the starting point for deriving the spatially-smoothed device model.

\section{Metal Oxide Semiconductors}

Different inorganic materials such as titanium dioxide $\left(\mathrm{TiO}_{2}\right)$, zinc oxidae $(\mathrm{ZnO})$, tin oxide $\left(\mathrm{SnO}_{2}\right)$, indium oxide $\left(\mathrm{In}_{2} \mathrm{O}_{3}\right)$ and neobinium oxide $\left(\mathrm{Nb}_{2} \mathrm{O}_{5}\right)$ have been used as n-type metal oxide semiconductors in DSSCs [29]. From these metal oxide nanostructures, $\mathrm{TiO}_{2}$ and $\mathrm{ZnO}$ is of interest since they are advantageous over others as photoelectrode. Additonally, $\mathrm{TiO}_{2}$ and $\mathrm{ZnO}$ preparation is cheap and availability is abdudant so they can be suitable for reducing the cost of solar cell technology. 
Generally, $\mathrm{TiO}_{2}$ is present in nature in three crystalline forms: anatase, rutile and brokite. Out of which rutile is the common and most stable. $\mathrm{TiO}_{2}$ has widely used as wide band-gap semiconductor. Rutile $\mathrm{TiO}_{2}$, shows band gap energy as $3.03 \mathrm{eV}$, whereas anatase $\mathrm{TiO}_{2}$ exibits $3.2 \mathrm{eV}$ band gap [30]. $\mathrm{TiO}_{2}$ shows diversity of applications such as ceramic, glass, paper industries, refractory coating, electronic components, cosmetics, medicine, food technology, painting, farming, chemical catalysis etc [31]. All these diversified applications are possible due to its corrosion resistance, low cost, abundance, nontoxicity, stability, durability, decomposing organic pollutants etc. Generally, $\mathrm{TiO}_{2}$ shows ultraviolet light absorption from the solar light $[32,33] . \mathrm{TiO}_{2}$ shows photocatalytic activity and used for photodegradation of many organic molecules [34]. Nanocrystalline $\mathrm{TiO}_{2}$ exibits outstanding optical, catalytic, and dielectric properties which made it useful in many industrial applications such as solar cells, pigments, opacifiers, fillers and photocatalysts [35]. Till date many methods have been reported for sysnthesis of one-dimensional (1D) titania or titanate nanomaterials like sol-gel template method, combination of sol-gel processing with electrophoretic deposition, sonochemical synthesis, molten salt-assisted pyrolysis routes, anodic oxidative hydrolysis, inverse microemulsion method, metal organic chemical vapor deposition (MOCVD), hydrothermal method etc [36]. After coating of $\mathrm{TiO}_{2}$, generally thermal annealing is used for $\mathrm{TiO}_{2}$ crystallization which enhances refractive index, self-cleaning property [37].

$\mathrm{ZnO}$ generally shows hexagonal wurtzite crystalline with band gap of $3.3 \mathrm{eV}$ and possesses larger exciton binding energy of $60 \mathrm{meV}$ than $\mathrm{GaN}$ at room temperature showing bright UV luminescence emission [38]. ZnO also exibit high electron mobility as 115-155 $\mathrm{cm}^{2} \mathrm{~V}^{-1} \mathrm{~s}^{-1}$ than $\mathrm{TiO}_{2}[39]$. $\mathrm{ZnO}$ has of interest due to its applications in different areas such as light-emitting diodes, ultraviolet lasers, high performance nanosensors, field emission devices, piezoelectric nanogenerators, solar cells and nanopiezotronics [40]. $\mathrm{ZnO}$ is a used as acceptor layer in solar cell due to its excellent properties like non-toxic, low cost, earth- 
abundant material with multiple solution deposition routes for preparation of thin films [41]. $\mathrm{ZnO}$ is commonly used as n-type layers for inverted $\mathrm{BHJ}$ cells [42]. As in comparision to other n-type metal oxides, $\mathrm{ZnO}$ is an ideal as it has environmental stability, high electron mobility, wide bandgap, high transparency $[43,44]$. There are many methods which has been reported for coating of $\mathrm{ZnO}$ like sol-gel, electrodeposition, chemical vapor deposition, spray pyrolysis, pulsed laser deposition, magnetron sputtering and hydrothermal [45].

\section{Improvements in OSCs and DSSCs}

The active layer of organic or dye sesitized soalr cell made up of donor(D), acceptor (A) and $\pi$-linkages type of organic semiconductors. Researcher are modulating different combinations of $\mathrm{D}, \mathrm{A}$ and $\pi$-linkages which results in different organic molecules with different efficiencies. Herein Table 1 complies some recent work done aiming towards improvement in OSCs and DSSCs followed by discussion regarding chemistry behind difference in results obtained.

Table 1. Some recent work done aiming towards improvement in OSCs and DSSCs 


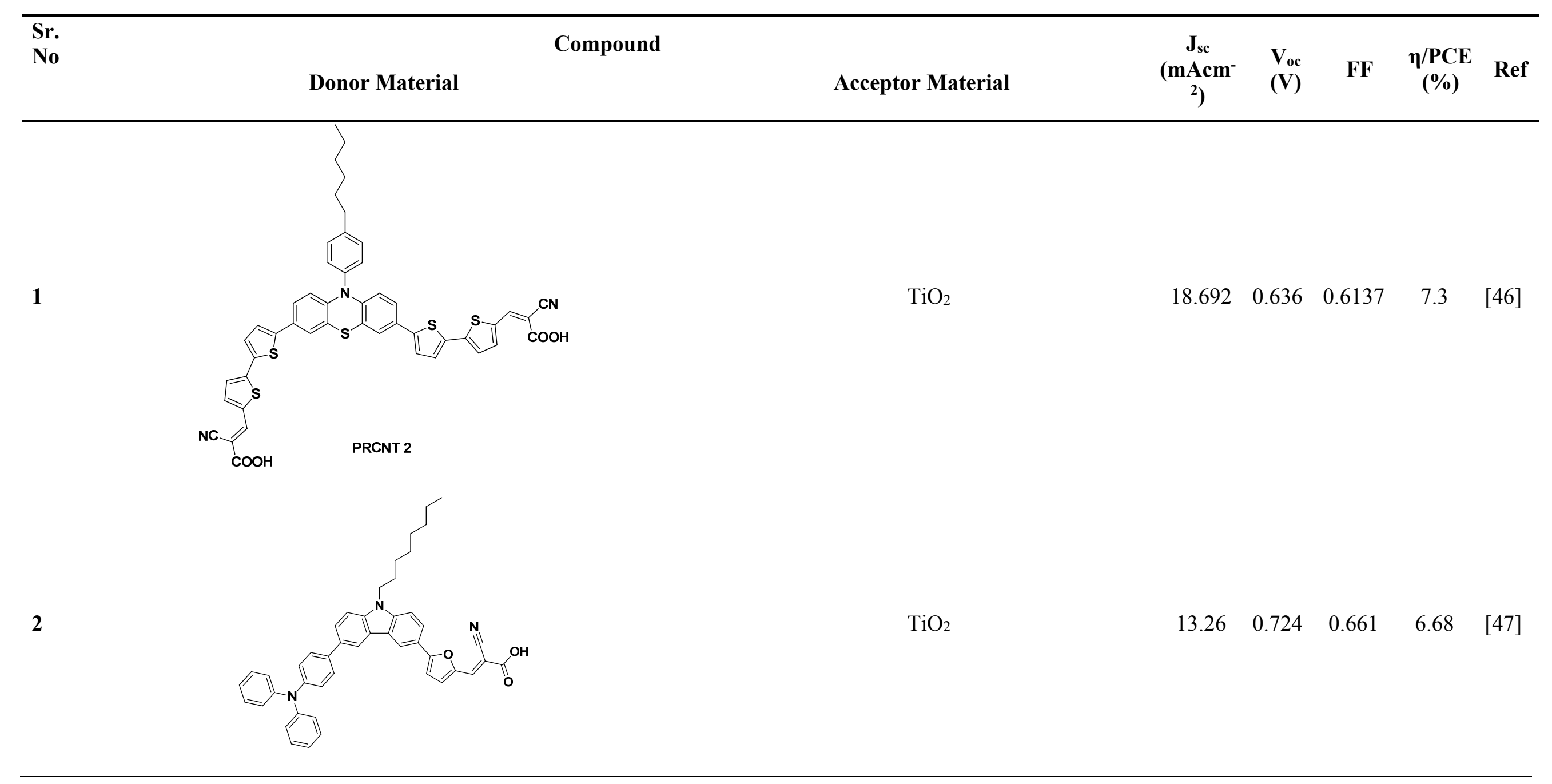


3

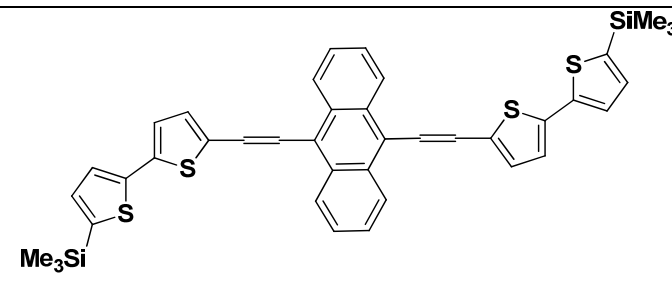

4

5
1-(3 methoxycarbonylpropyl)-1-phenyl-[6,6]-

methano-fullerene (PCBM)
PCBM

$\mathrm{TiO}_{2}$
5.94

$0.776 \quad 0.3080$

1.42

[49]

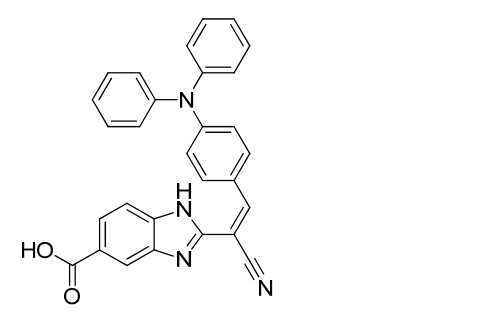

$\begin{array}{lllll}7.547 & 0.62 & 0.6304 & 3.47 & {[50]}\end{array}$ 

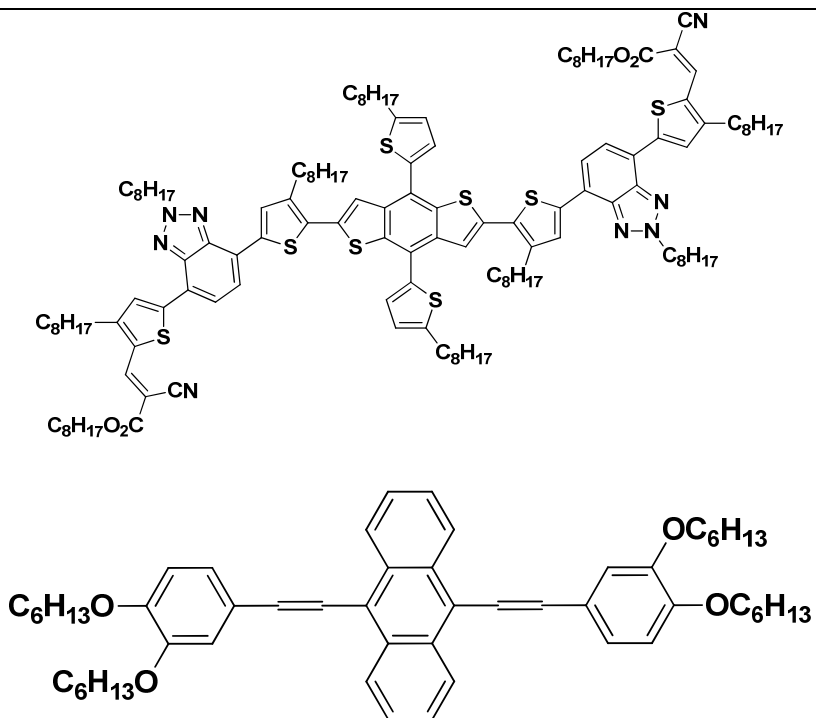

PCBM

PCBM $\begin{array}{lll}3.10 & 0.89 & 0.45\end{array}$

$1.27 \quad[52]$

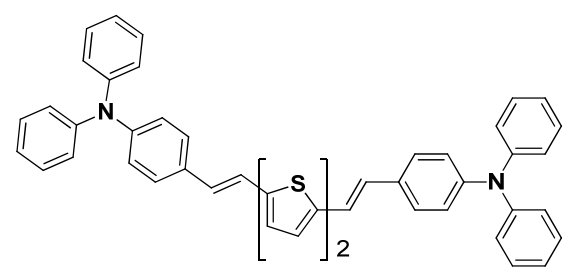



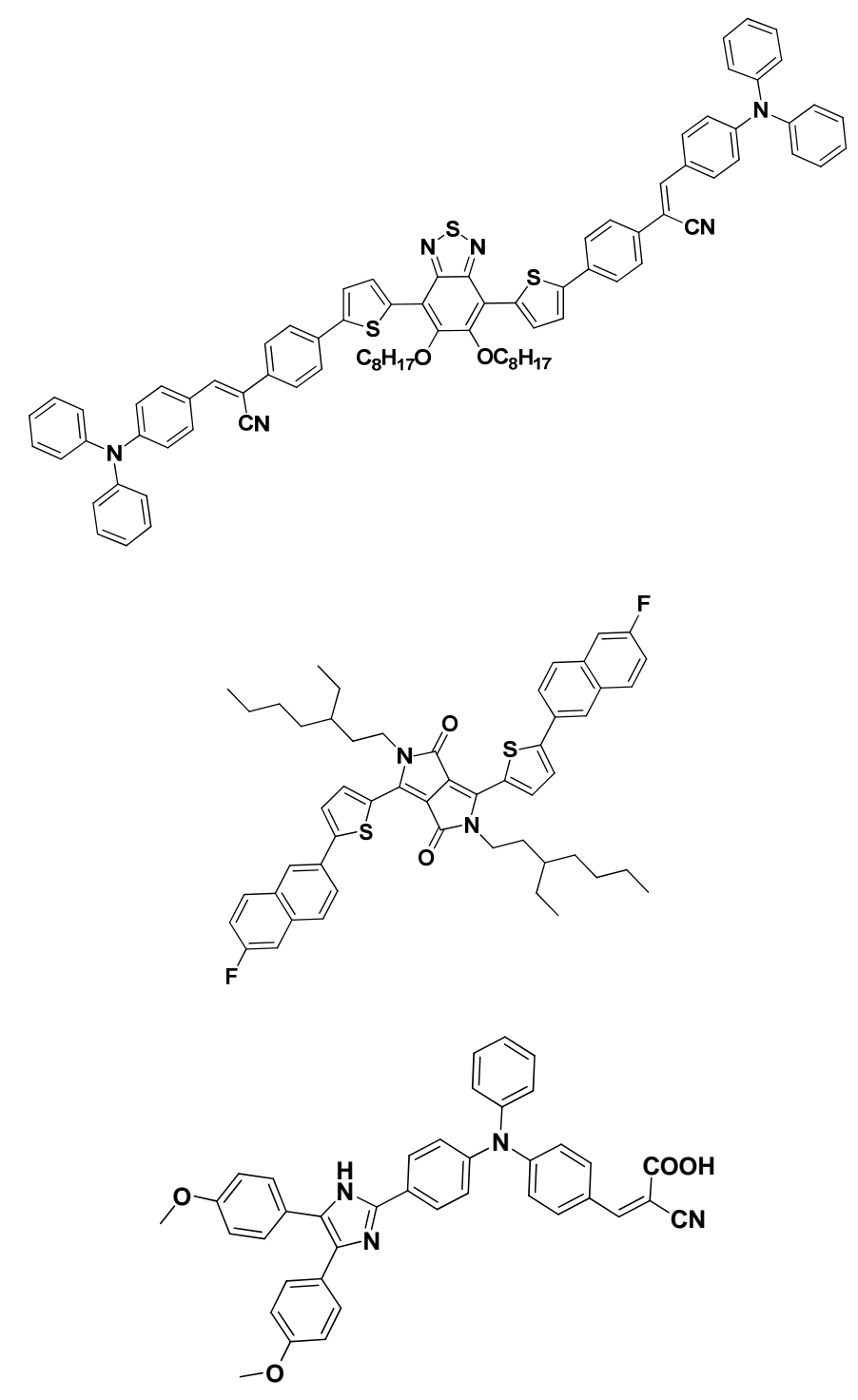

$\mathrm{TiO}_{2}$

8.60

0.63

0.75

4.11 


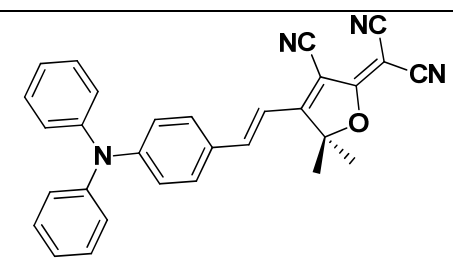

13

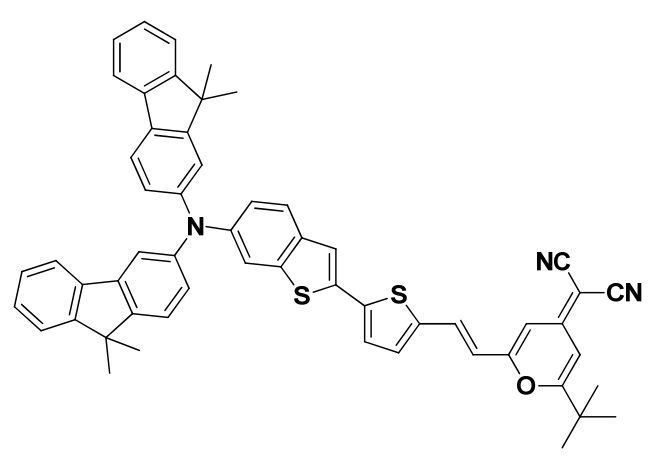

14
[6,6]-phenyl-C71-butyricacidmethylester $\left(\mathrm{PC}_{71} \mathrm{BM}\right)$

(C $71-\mathrm{PCBM})$

$\mathrm{PC}_{71} \mathrm{BM}$ $\begin{array}{lllll}8.74 & 0.93 & 0.30 & 2.44 & {[57]}\end{array}$

$\left.\begin{array}{lllll}9.64 & 0.80 & 42 & 3.22 & {[58}\end{array}\right]$

$\left.\begin{array}{lllll}10.80 & 0.89 & 0.42 & 4.04 & {[59}\end{array}\right]$ 


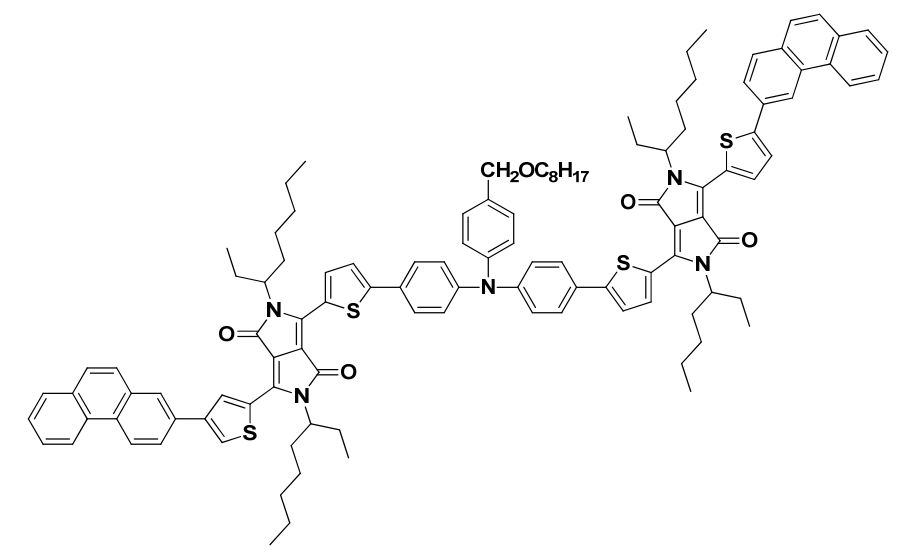

16

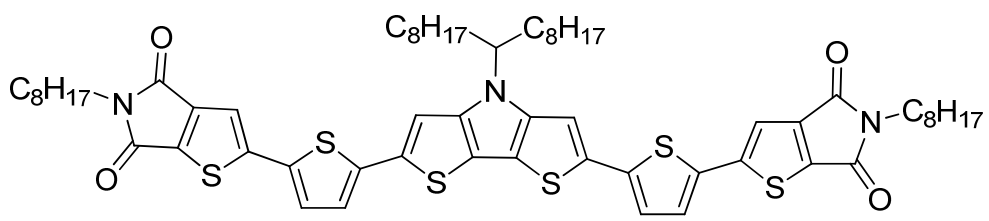

17

18
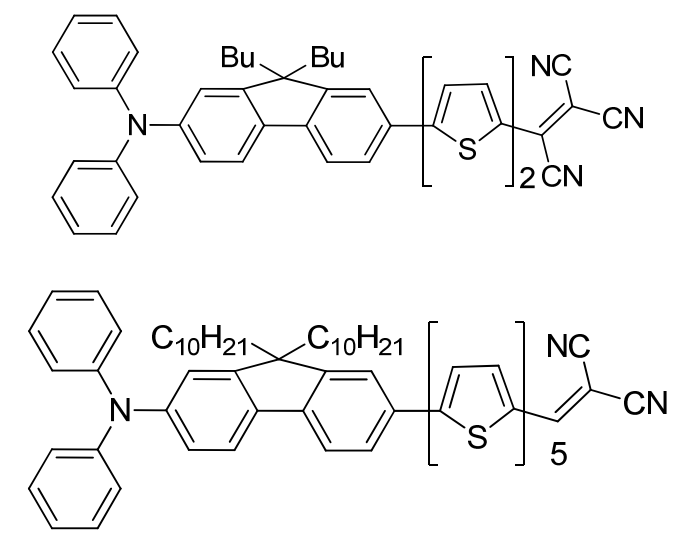

PCBM 
19

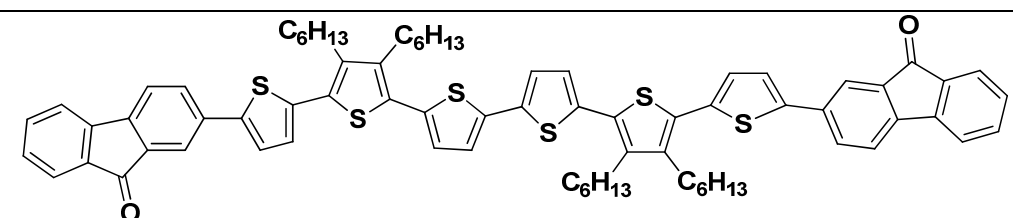

20

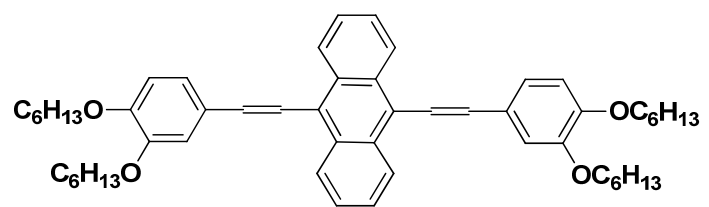

21

22
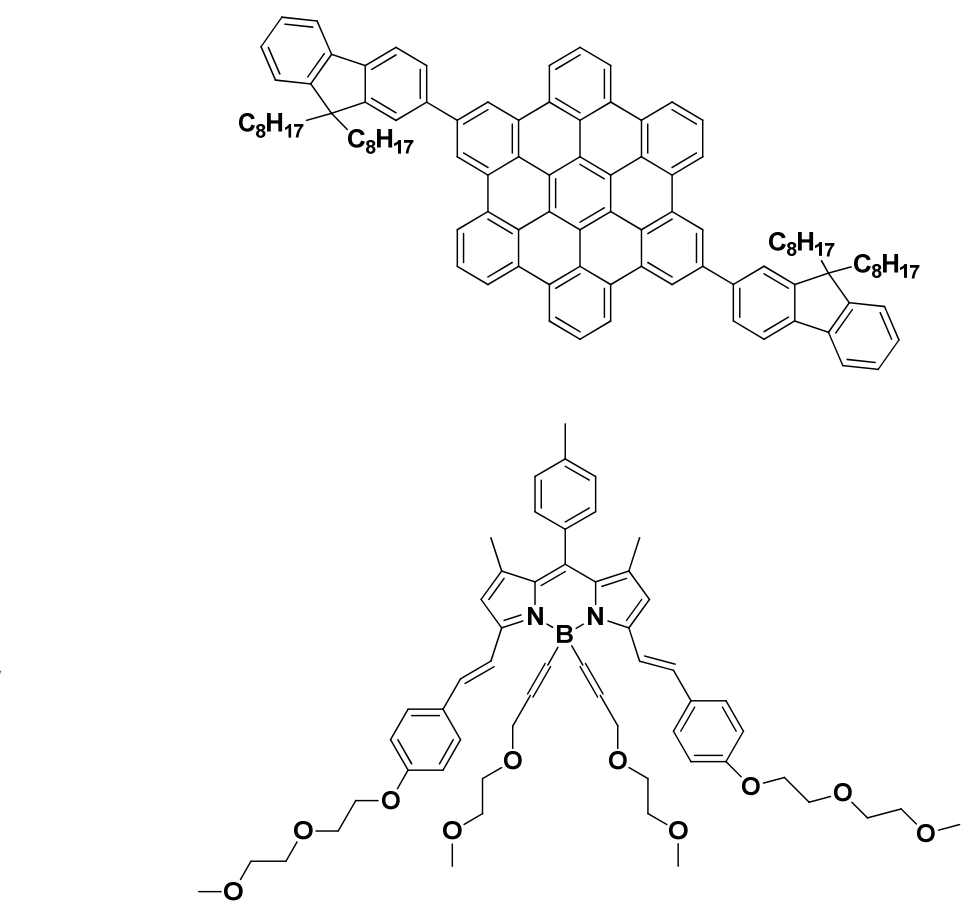

[6,6]-phenyl-C61-butyric acid methyl ester

(PCBM)

PCBM

$\mathrm{PC}_{61} \mathrm{BM}$

PCBM
3.03

0.70

0.37

0.77

[64]

2.62

0.96 $\begin{array}{lllll}2.68 & 0.90 & 0.61 & 1.46 & {[66]}\end{array}$

$\begin{array}{lllll}4.14 & 0.753 & 44 & 1.34 & {[67]}\end{array}$ 

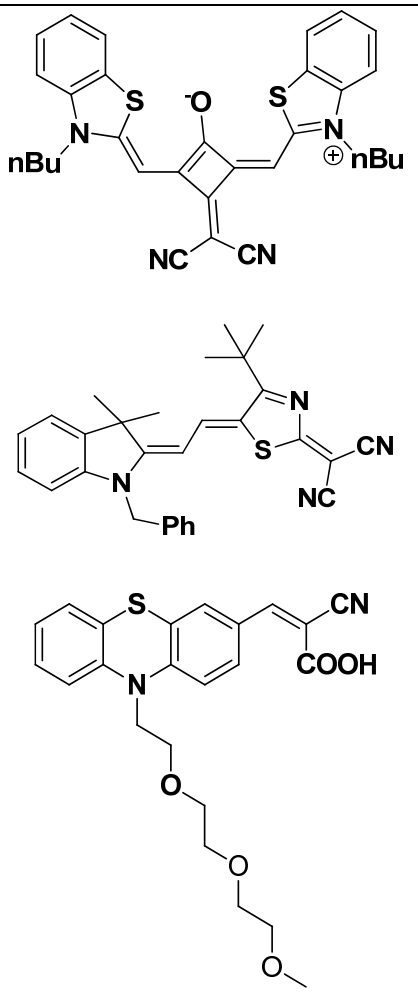

26

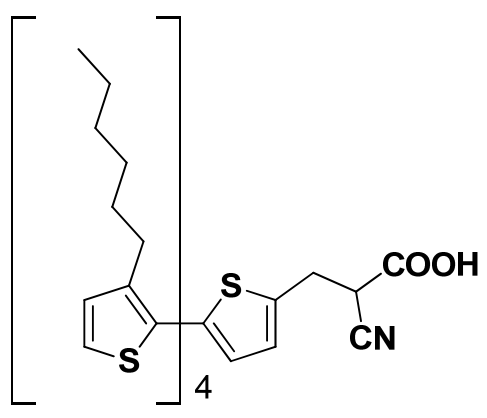

25
PCBM

$\mathrm{TiO}_{2}$

$\mathrm{TiO}_{2}$ $\begin{array}{lllll}8.36 & 0.66 & 0.74 & 4.07 & {[70]}\end{array}$

$\left.\begin{array}{lllll}6.3 & 0.76 & 0.36 & 1.74 & {[69}\end{array}\right]$

$\begin{array}{lllll}4.65 & 0.79 & 0.63 & 2.32 & {[71]}\end{array}$ 

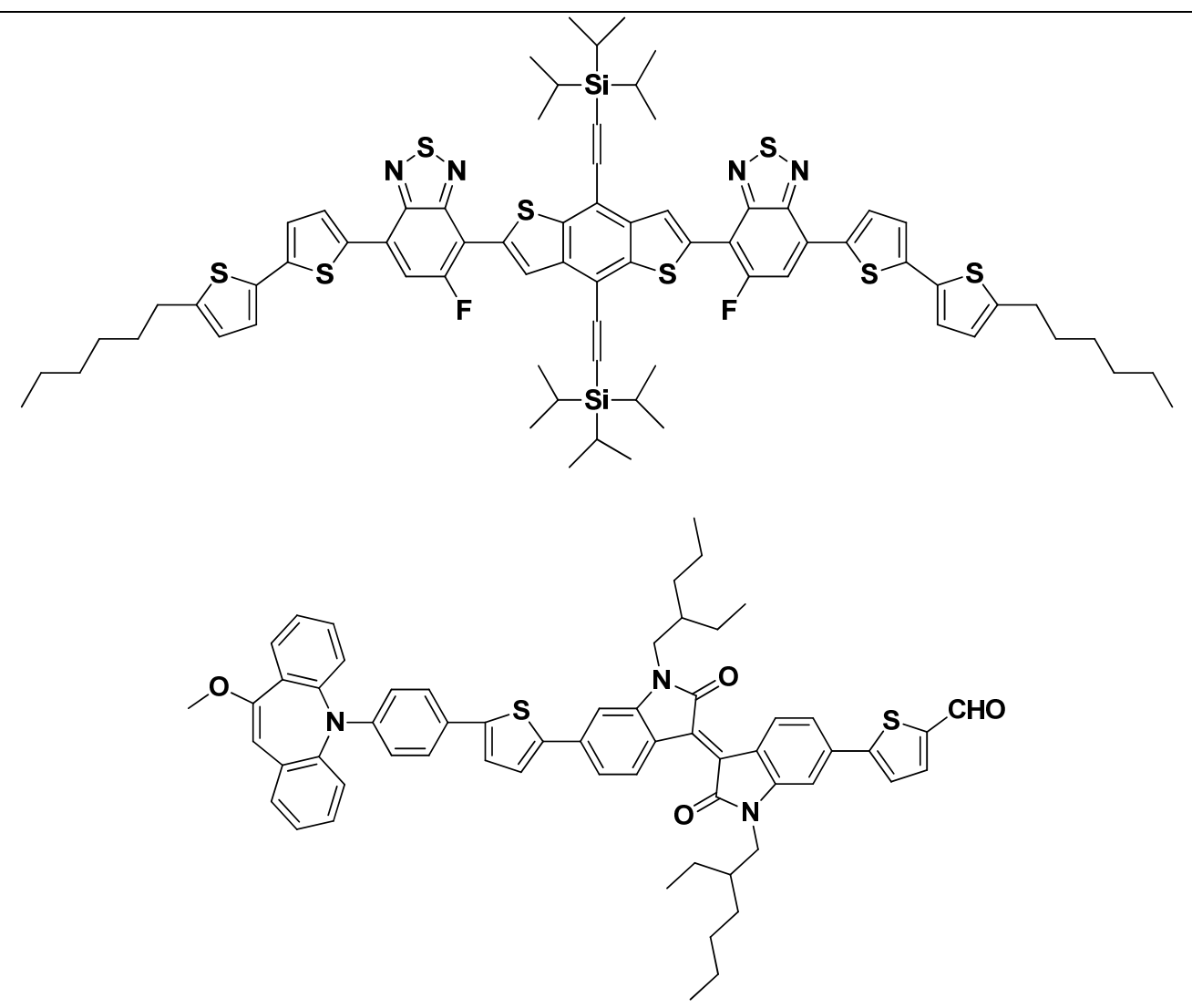


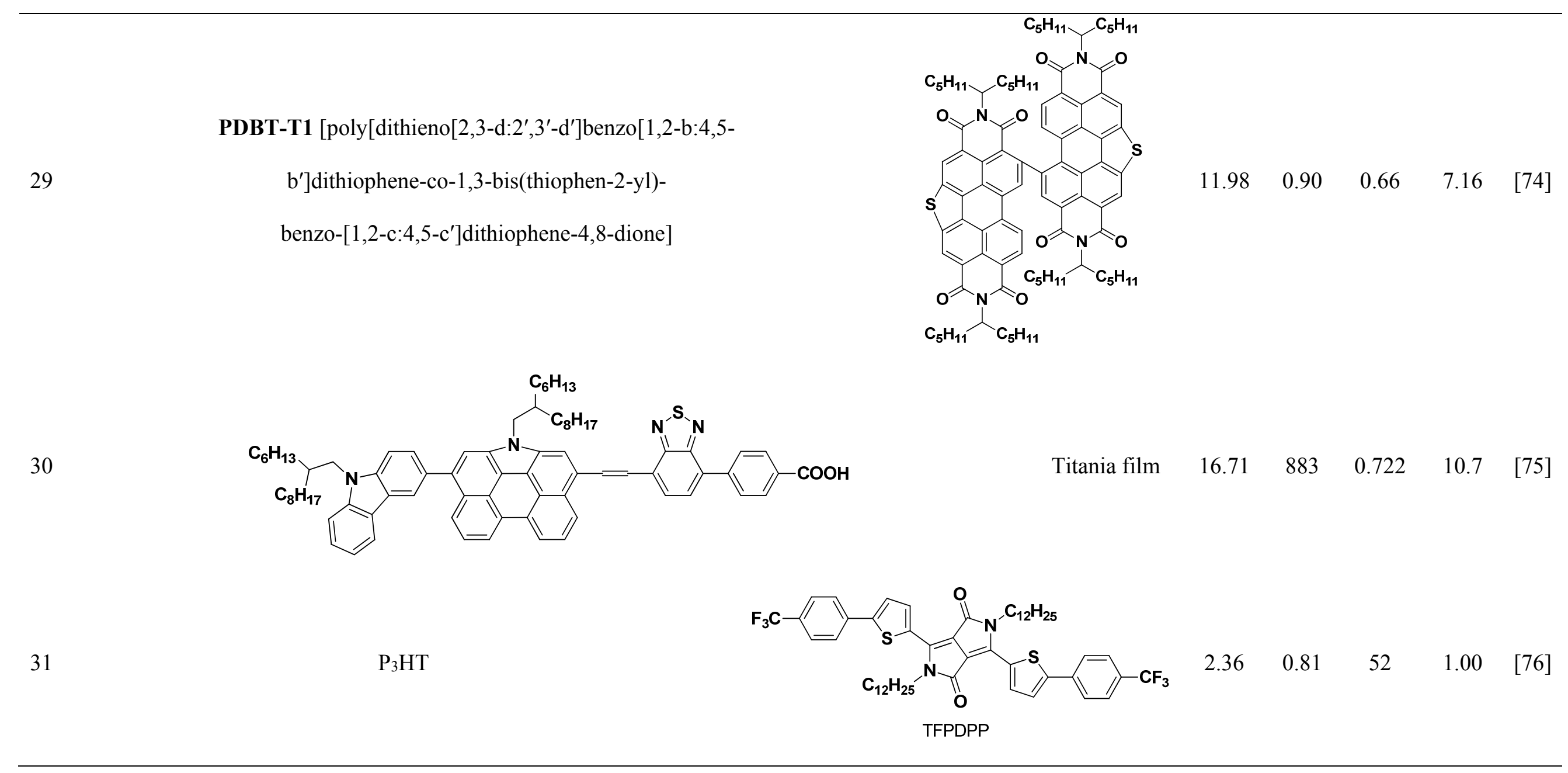




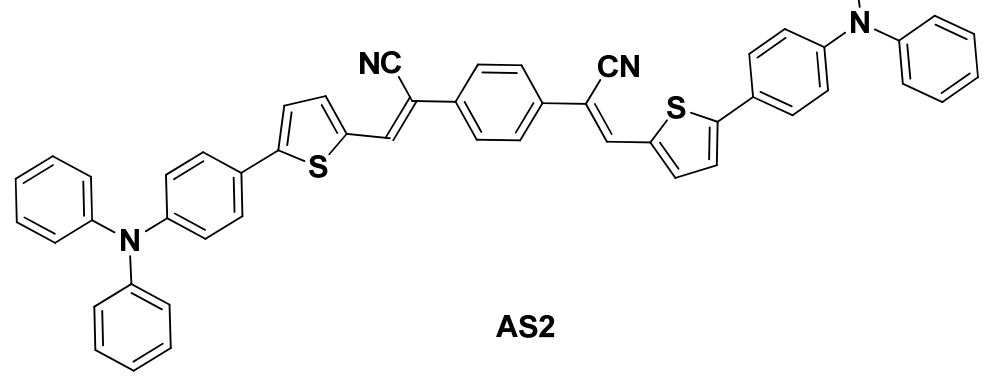

33

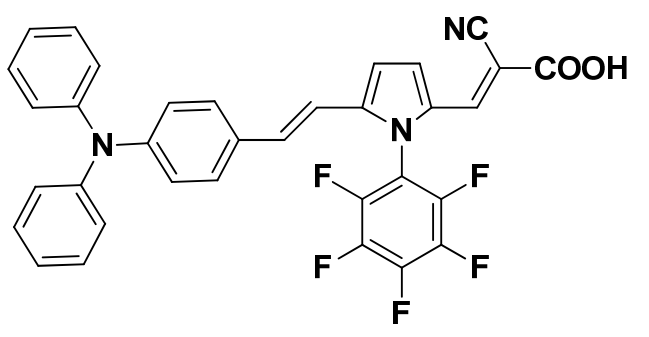

34

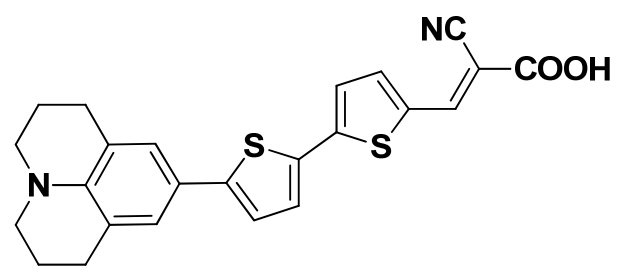

35
[6,6]-phenyl-C61-butyric acid

$\begin{array}{lllll}8.01 & 0.88 & 0.58 & 4.10 & {[77]}\end{array}$
$\mathrm{TiO}_{2}$

$\mathrm{TiO}_{2}$

410

0.64

2.6

[79]

$\mathrm{TiO}_{2}$

8.59

0.75

4.93

[80] 


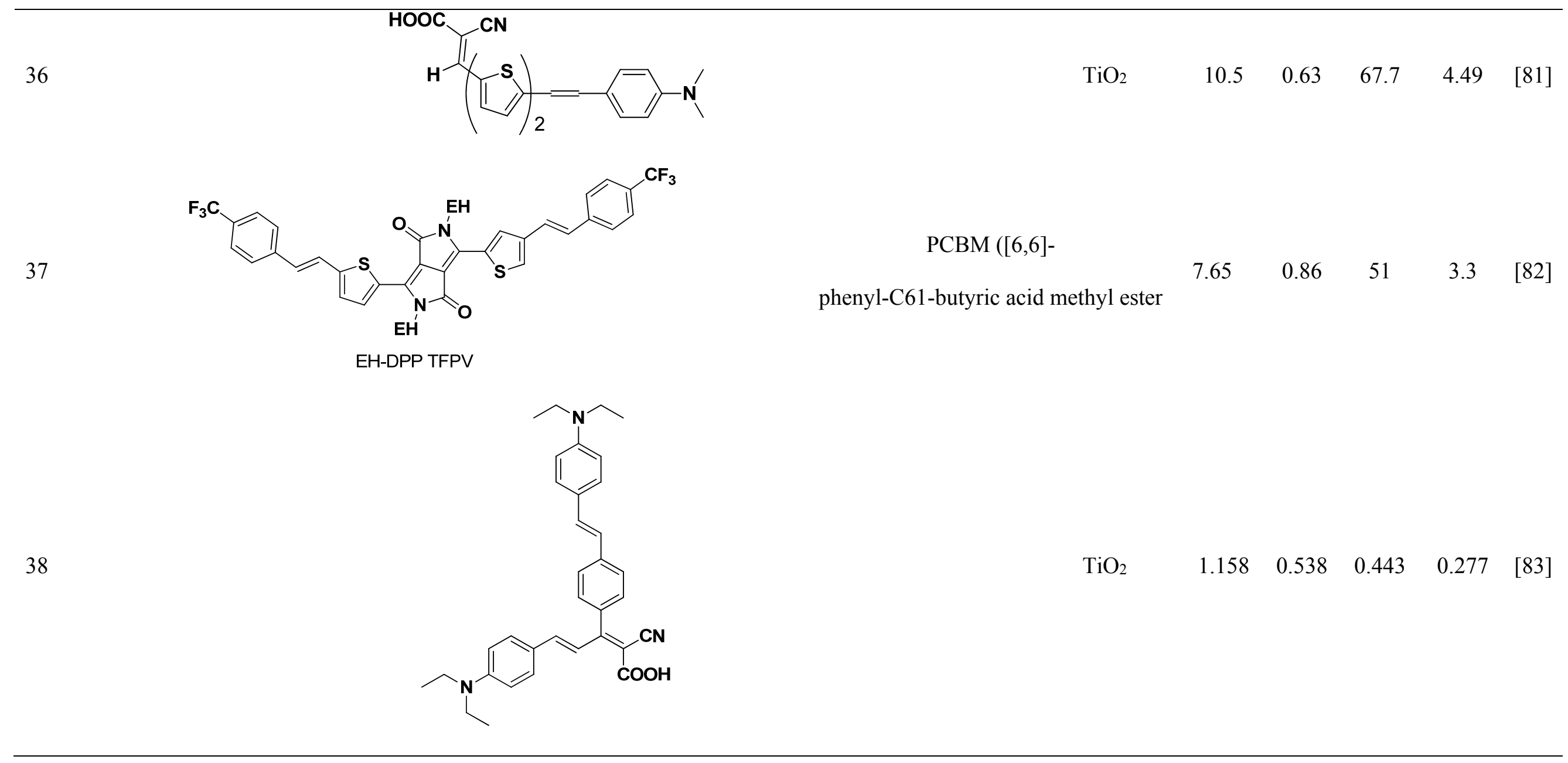




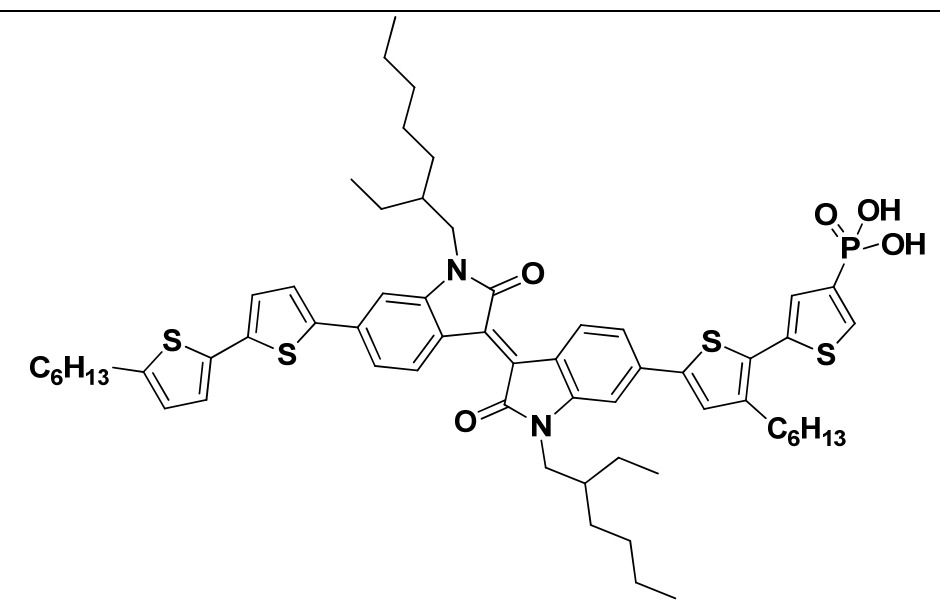

40

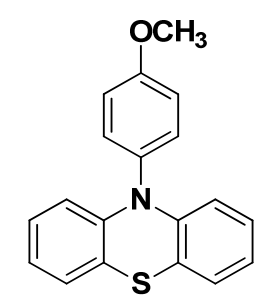

41

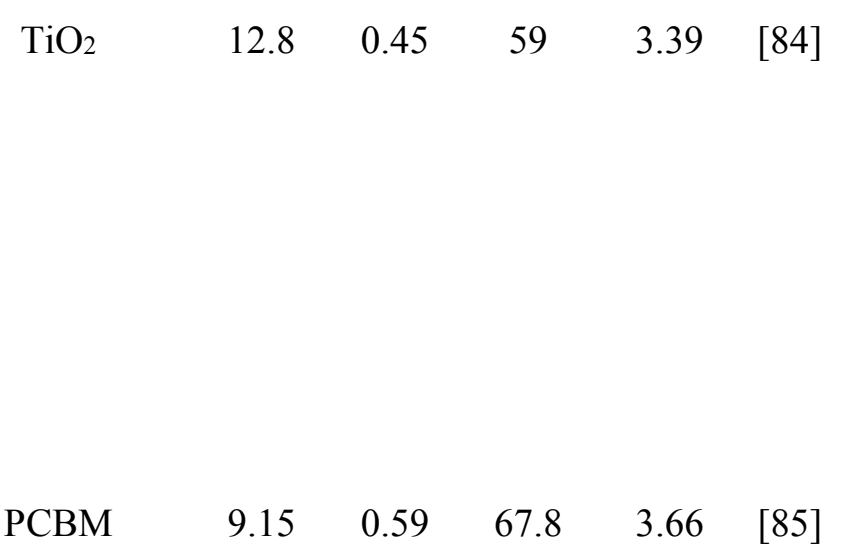

$\begin{array}{llllll}\text { fullerene } \mathrm{C}_{60} & 3.65 & 0.89 & 0.36 & 1.17 & {[86]}\end{array}$ 


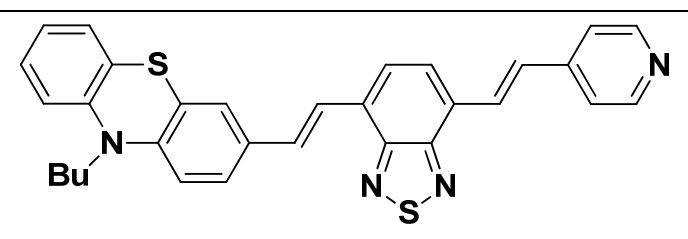

43

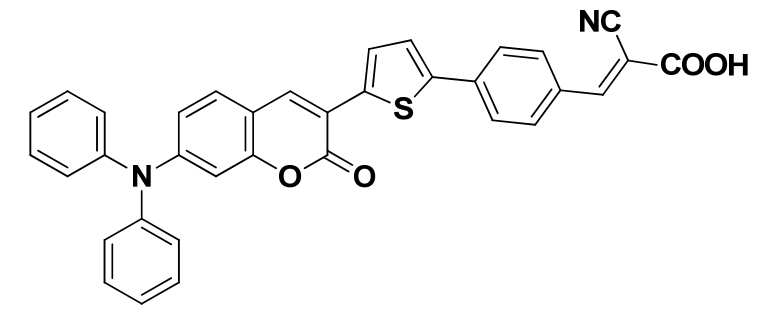

44

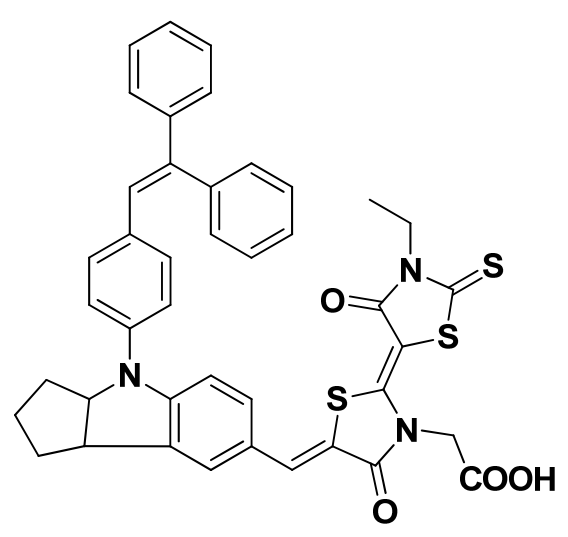

D149
$\begin{array}{llllll}\mathrm{TiO}_{2} & 5.65 & 564 & 0.62 & 1.97 & {[87]}\end{array}$

$\mathrm{TiO}_{2}$

$\left.\begin{array}{lllll}14.33 & 0.69 & 0.63 & 6.24 & {[88}\end{array}\right]$

$\begin{array}{llllll}\mathrm{TiO}_{2} & 15.14 & 0.625 & 0.64 & 6.09 & {[89]}\end{array}$ 

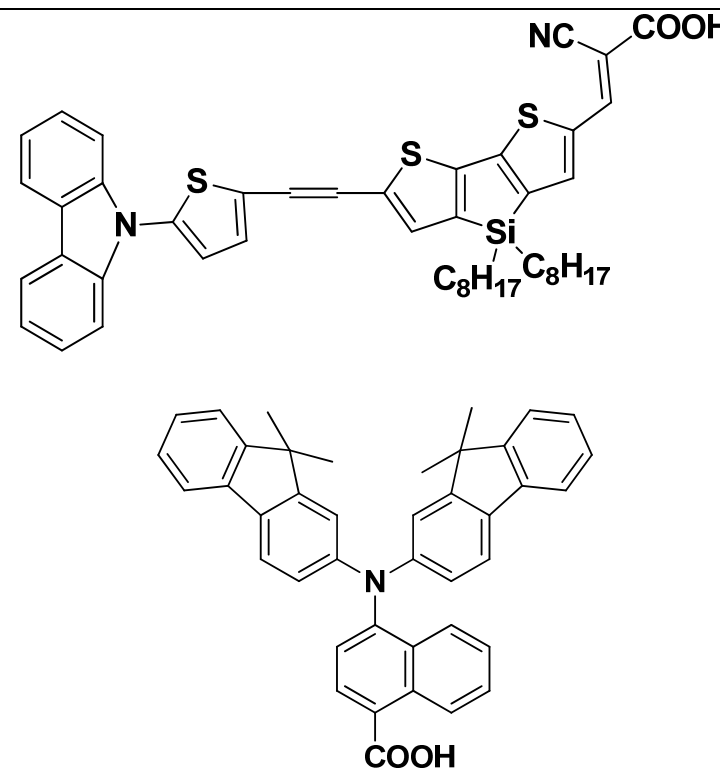

$\begin{array}{llllll}\mathrm{TiO}_{2} & 15.6 & 703 & 74.9 & 8.2 & {[91]}\end{array}$

HC-A4

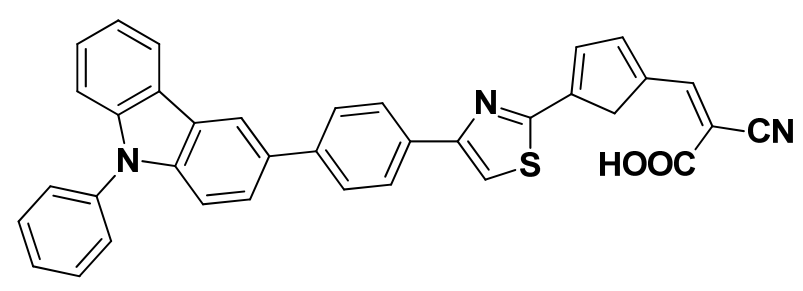

$\mathrm{TiO}_{2}$ 


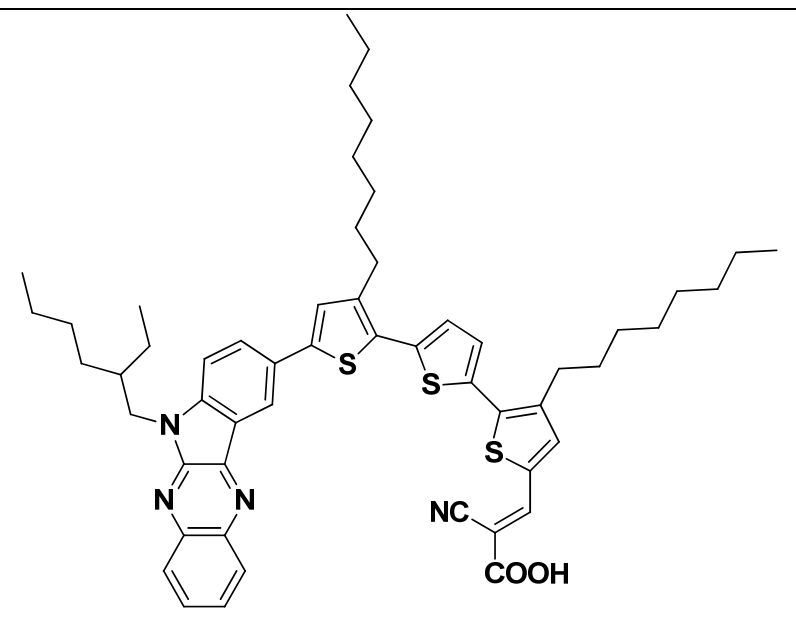

$\mathrm{TiO}_{2}$

$\left.\begin{array}{lllll}16.0 & 708 & 0.67 & 7.62 & {[93}\end{array}\right]$

49

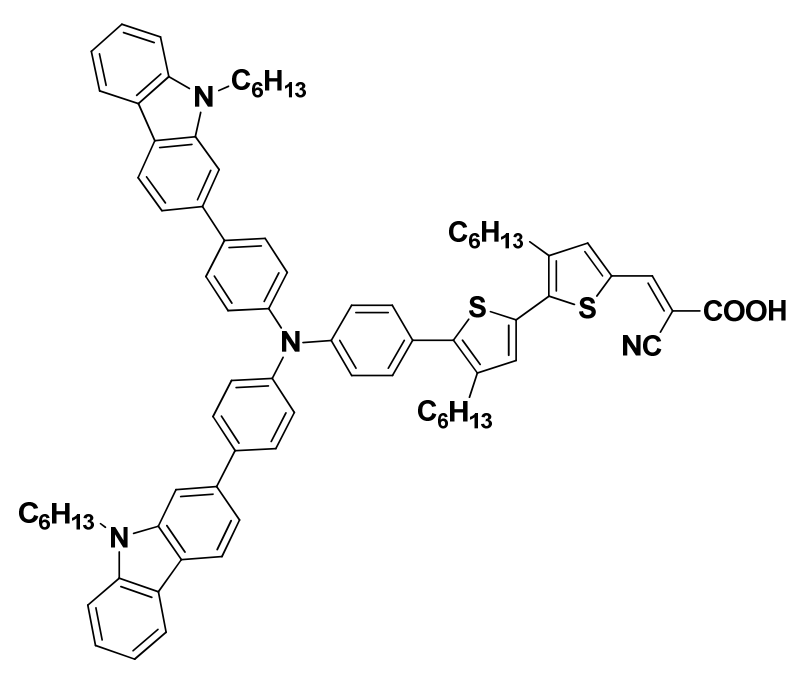

$\mathrm{TiO}_{2}$

$\begin{array}{lllll}11.22 & 0.825 & 0.721 & 6.67 & {[94]}\end{array}$ 


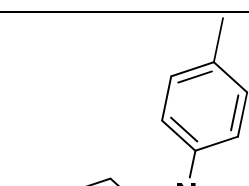

(N)

51

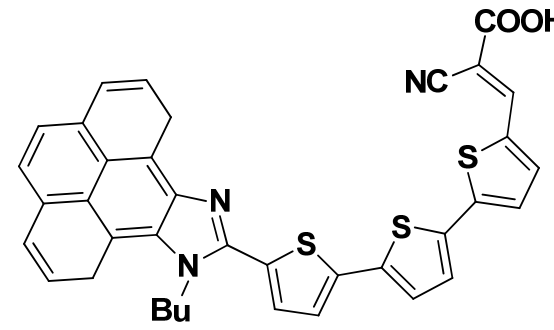

$\mathrm{C}_{6} \mathrm{H}_{13}$

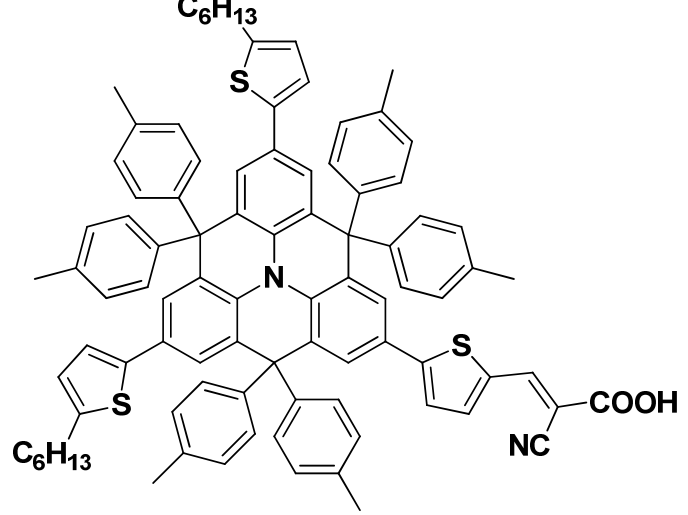

52
$\mathrm{TiO}_{2}$

$11.63 \quad 754$

0.73

6.37

[95]

$\mathrm{TiO}_{2}$

$\begin{array}{lllll}8.61 & 704 & 71.7 & 4.35 & \text { [97] }\end{array}$ 


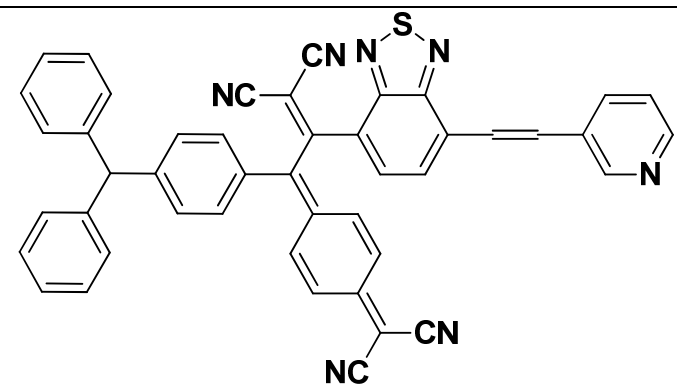

$\begin{array}{llllll}\mathrm{PC}_{71} \mathrm{BM} & 11.28 & 0.92 & 0.60 & 6.02 & {[98}\end{array}$

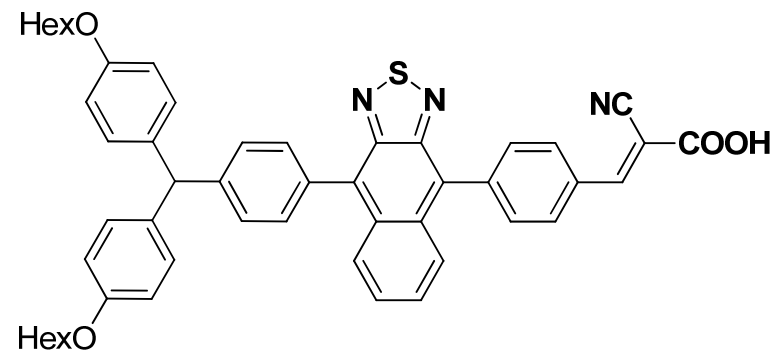

$\begin{array}{llllll}\mathrm{TiO}_{2} & 15.09 & 0.689 & 0.72 & 7.53 & {[99}\end{array}$ 


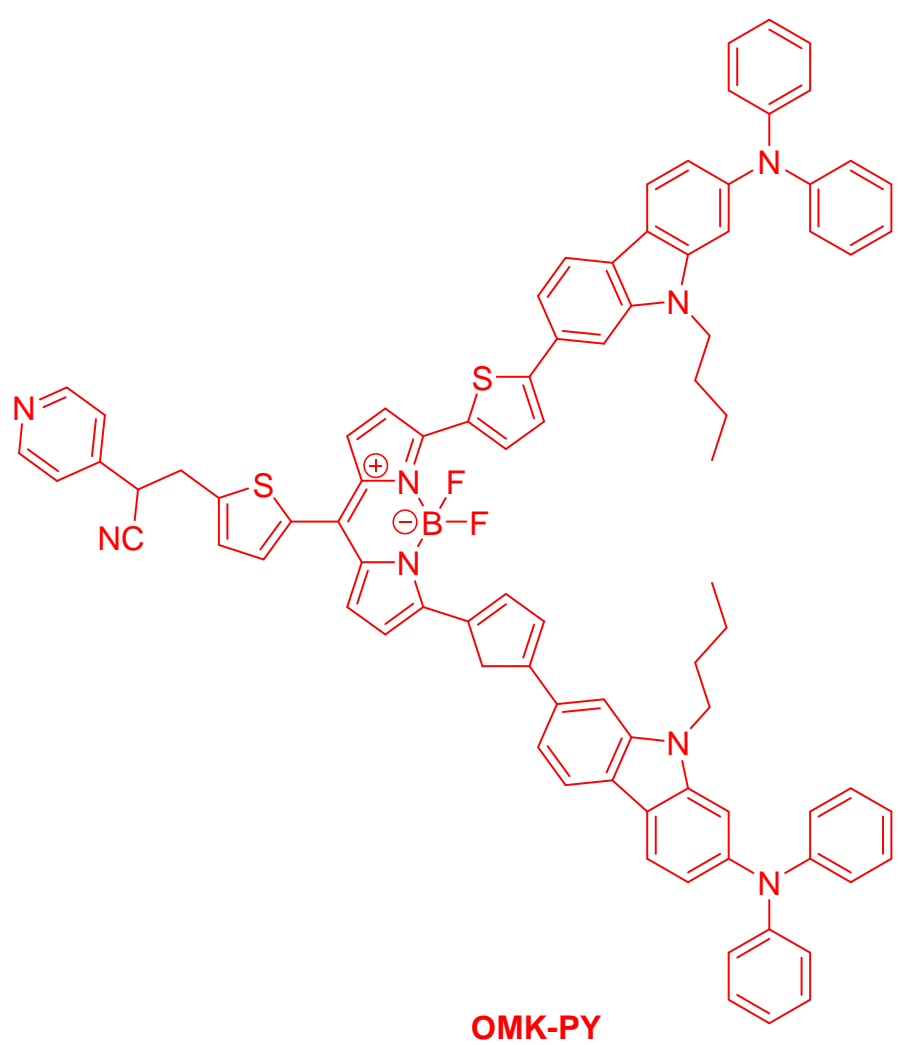




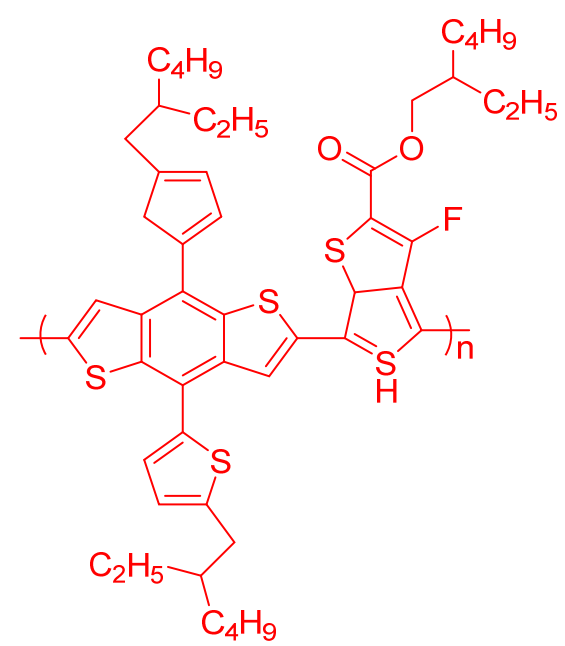

PTB7:Th

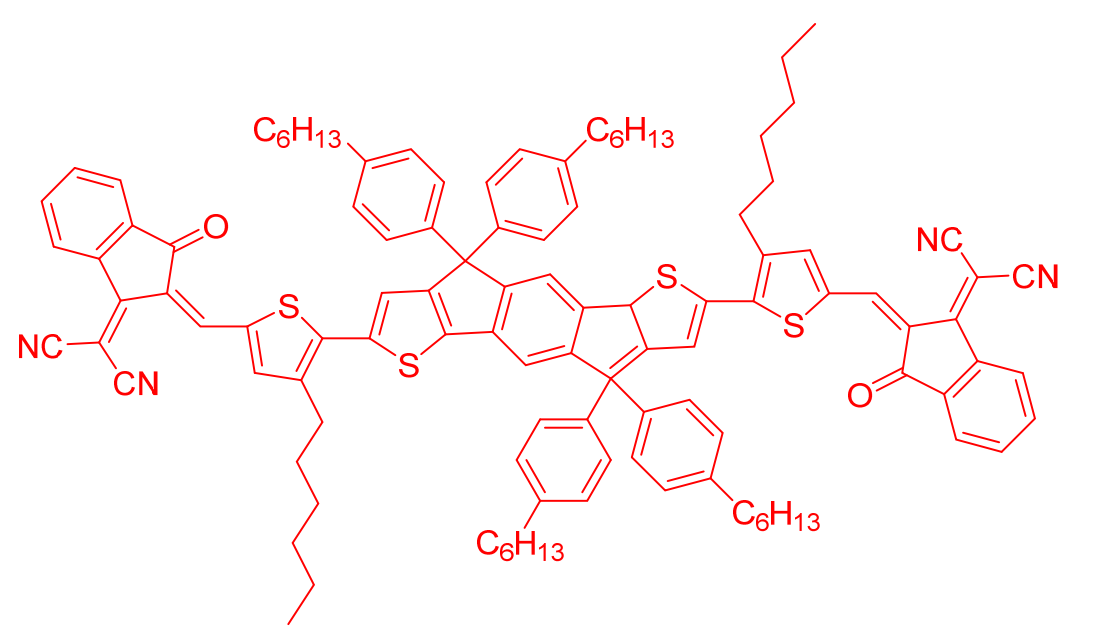

IEIC3

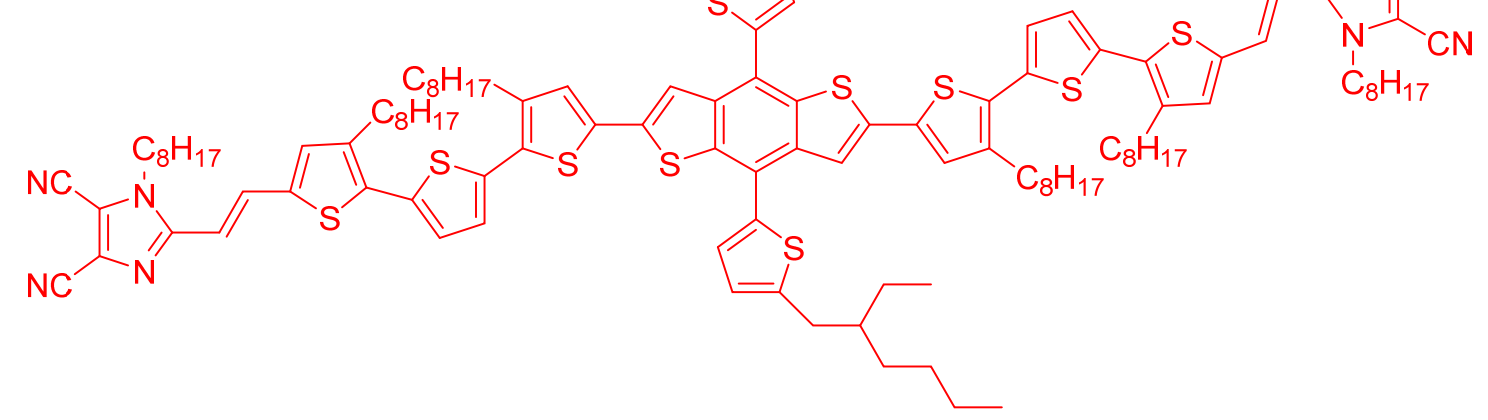




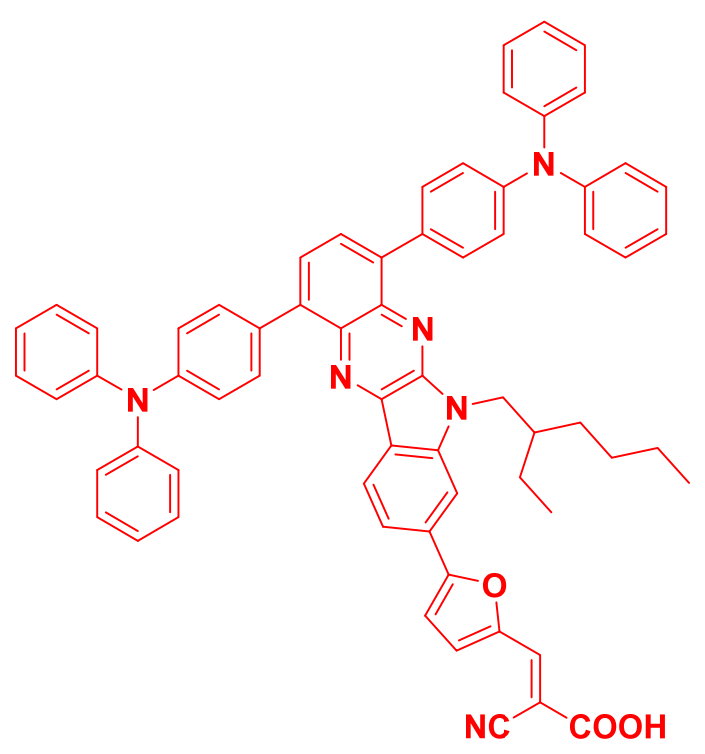

$\mathrm{TiO}_{2}$

$\begin{array}{lll}0.817 & 67.3 \quad 7.09\end{array}$

QX23 


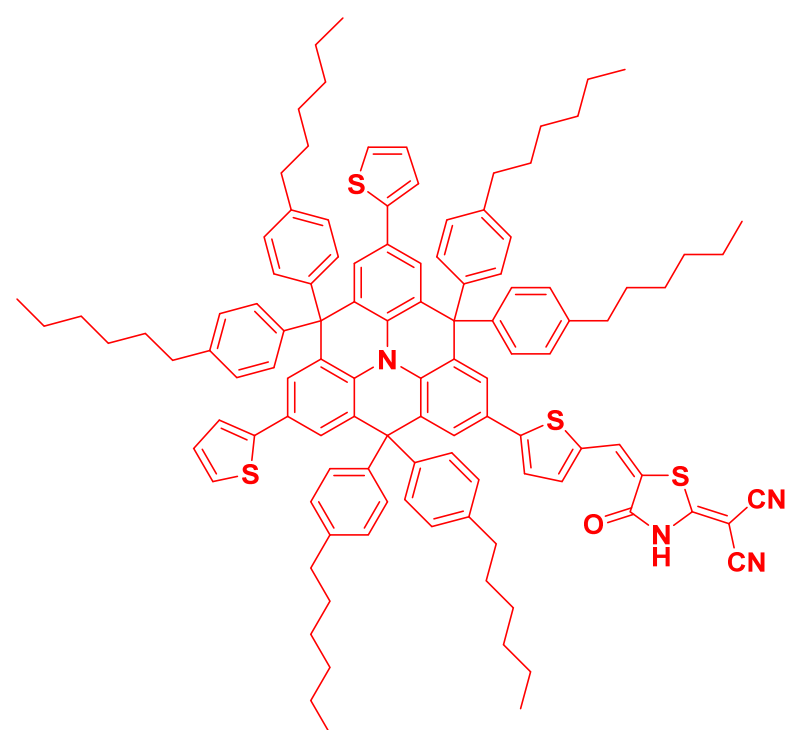

NUIST1
$\mathrm{TiO}_{2}$

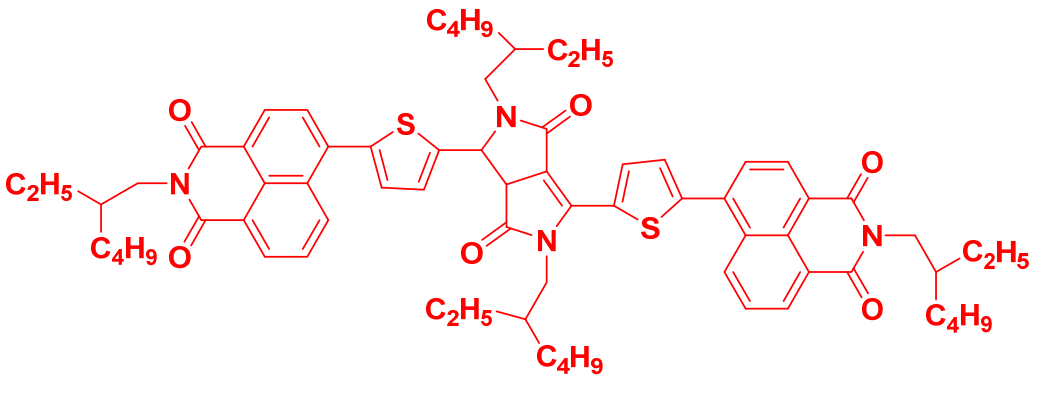

NI-DPP 


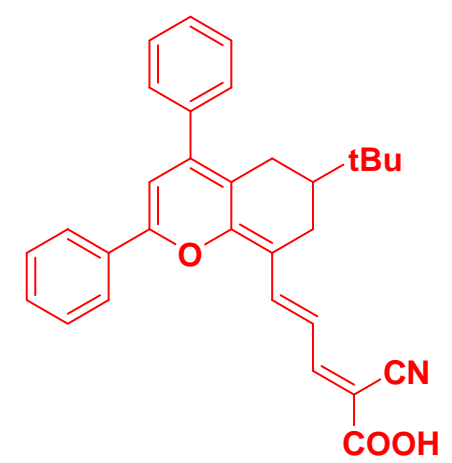


Hyo Jeong Jo reported synthesis of novel twin-anchoring donor acceptor $\pi$-conjugated (D- $\pi$ A) organic dyes PRSCN2 and PRTCN2 (dye 1). These organic dyes have phenothiazine moiety as a donor, different numbers of thiophene units as a $\pi$-conjugated unit, and a cyanoacetic acid as an acceptor group. PRTCN2 gives higher efficiency than PRSCN2 due to higher HOMO energy level and high molar extinction coefficients or strong $\pi$ - $\pi$ interaction by introduction of bithiophene unit [46].

Novel carbazole organic D-D- $\pi$-A dyes containing either a furan or a thiophene unit as the conjugated bridge have been designed and synthesized by Jinxiang He et al. carbazole containing linear or branched alkyl side chain acts as an electron donor, triphenylamine acts as an electron-donating group and cyanoarylic acid acts as an electron acceptor. From these dyes an octyl-substituted carbazole and disubstituted furan (dye 2) has shown the best photovoltaic performance. This behaviour of dyes may be due to alkyl chains self-assembling on $\mathrm{TiO}_{2}$ film and a longer distance between the $\mathrm{TiO}_{2}$ film and electrolyte by lengthening of the alkyl chains, which block the recapture of the photo conditions, which indicated that the introduction of the alkyl chains into the carbazole moiety can inhibit the charge recombination and increases cell efficiency [47].

The photovoltaic behaviour of donor materials containing thiophene based 2-trimethylsilylbithienyl moiety attached to different cores via acetylenic spacers was reported. In that study, Silvia Colella and co-workers gives the comparison of three compounds by the substitution of the bi-thienylene, electron withdrawing benzothiadiazole and electron-rich anthracene central core respectively for three compounds. Amongst them compound containing anthracene group (dye 3) found highest efficiency due to the more extensive conjugation of anthracene group which increases the HOMO energy as compare to the benzothiazole group which lowers the LUMO energy as it has electron withdrawing property. An donor molecules 
suppose to show good $\pi-\pi$ stacking interactions which gives better $\mathrm{J}_{\mathrm{SC}}$ and also donor should have low intermolecular overlap with the acceptor [48].

Annulated thiophene perylene bisimides and their triphenylamine based oligomers was synthesized and reported by Hyunbong Choi et al. Triphenylamine-based oligomer units used as donor in OSCs as these compounds exhibit broad absorptions with appropriate energy difference in the LUMO of donor-acceptor [49].

Four Benzimidazole based metal free organic dyes (D- $\pi$-A) namely 2-(4(diethylamino)phenyl)-benzimidazole-5-carboxylic acid (EB), 2-(4-(diphenylamino)phenyl)benzimidazole-5-carboxy lic acid (PB), 2-(1-cyano-2-(4-(diethylamino)phenyl)vinyl)benzimidazole- 5-carboxylic acid (ECB) and 2-(1-cyano-2-(4-(diphenylamino) phenyl)vinyl)benzimidazole-5-carboxylic acid (PCB) with N,N-diethylaniline and triphenylamine as donors and benzimidazole derivatives as $\pi$-bridge as well as acceptor was reported. Among these dyes, triphenylamine donor based dyes (PCB and PB) show higher efficiency compared to N,N-diethylaniline donor based dyes (ECB and EB). Introduction of cyanovinyl group in dyes PCB (dye 5) and PB increases the overall efficiency than the dyes without cyanovinyl group ECB an EB. This was due to the reduced band gap, red shift absorption bands in the visible region, longer recombination resistance and high electron lifetime [50].

Yanhua Chen and co-workers reported synthesis and fabrication of $A_{1}-\pi-A_{2}-D-A_{2}-\pi-A_{1}$ type molecule with electron-withdrawing group attached to a benzo[1,2-b:4,5-b0]dithiophene (BDT) core through electron-accepting benzotriazole in OSCs. D(CATBTzT)BDT small molecule gives 3.61\% due to efficiency good thermal stability and deep HOMO level [51]. A series of five extended arylacetylenes was synthesized and reported. The highest PCE has been obtained for anthracene-based arylacetylene A-P6t. Here results suggested that acetylenic substitution for olefinic linkers on the molecular cores improves efficiency [52]. 
Thermally stable donor materials containing thiophene or bithiophene and triphenylamine unit attached with conjugated bonds used for the fabrication of OSCs with $[6,6]$-phenyl $\mathrm{C}_{61-}$ butyric acid methyl ester (PCBM). Jongchul Kwon et al. explained effect of the morphology of dyes: PCBM on the cell efficiency. Ratio of 1:1 (dye 8: PCBM) films exhibited aggregation which may be due to the donor-donor interaction as donor concentration was high at this ratio. However, 1:4 (dye 8: PCBM) films shows homogeneous and good morphology [53].

Donor- $\pi$-acceptor- $\pi$-donor (D- $\pi-A-\pi-D)$ typed two novel small molecules BDPTBT and BDATBT with 5,6-bis-(octyloxy)benzo[c][1,2,5]thiadiazole (DOBT) as electronwithdrawing core (A), and triphenylamine (TPA) as electron-donating side group (D) and the benzene and ethynylbenzene as $\pi$-linkage were designed and synthesized by Lihui Wang coworkers. The highest efficiency for D-A-D-typed benzothiadiazole (BT)-TPA based solution-processed small molecules (dye 9) could be caused by the linkage group of styrene and 2-phenylacrylonitrile which could not only improve the molecular planarity but also facilitate the photoinduced charge dissociation and hole mobility [54].

Diketopyrrolopyrrole molecule with (fluoronaphthyl)thienyl as endgroups was described by Rui Zhou et al. for bulk heterojunction OSCs. The compound with Fluorine shows good efficiency than compound without Fluorine. This was due to thermally-annealed thin film of DPP(TFNa)2 possesses more homogenous morphology with red-shifted absorption [55].

Ximing Chen et al. were report synthesis of different imidazole derivatives with triphenylamine and the 2-cyanoacetic acid as acceptor group to prepare two new 2D- $\pi$-A dyes coded as CD-4 and CD-6. Addition of imidazole derivatives in triphenylamine core gave a big difference to the photovoltaic performances of DSSCs. By introducing the pmethoxyphenyl group to imidazole part (CD-4) gives higher Joc and Voc than the thiophene group to imidazole part (CD-6). This was due to CD-6 having a better planarity on the 
imidazole unit than that of CD-4, which leads to the formation of $\pi$-stacked aggregation. To dissociate the $\pi$-stacked sensitizer aggregation chenodeoxycholic acid (CDCA) is utilized as coadsorbent [56].

Four D-A type chromophores having 2-cyanomethylene-3-cyano-4,5,5-trimethyl-2,5dihydrofuran (TCF) group as acceptor was designed and synthesized. Min Ju Cho et al. compare the device performance of dye $12: \mathrm{P}_{71} \mathrm{BM}$ and observed that device made of dye 12: $\mathrm{P}_{71} \mathrm{BM}$ (1:2) gives higher efficiency of $2.44 \%$ than 1:1, 1:3, 1:4 compositions and concluded that different donating groups affects on absorption coefficients and the molecular energy levels of the chromophores [57].

Push-pull organic semiconductors containing N,N-(6-bis(9,9-dimethyl-9H-fluoren-2yl)amino benzo[b]thiophene (bisDMFABT) as donor and the different acceptors attached with thiophene or vinyl thiophene $\pi$-conjugation bridges were prepared and investigated for their photovoltaic properties by Jooyoung Kim and co-workers. The ICT (intramolecular charge transfer transition) band of TCF acceptor was significantly red-shifted in comparision to $\mathrm{NO}_{2}$ and DCBP accetor because of the better electron withdrawing property of TCF. This paper also suggested that TiOx can excellently used as optical spacer [58].

Another push-pull organic molecule DMM-TPA-Th2-MMN having planar fused triphenylamine (DMM-TPA) as donor and methylene malononitrile (MMN) as acceptor was reported. K. Do et al. used $\mathrm{PC}_{71} \mathrm{BM}$ with or without $\mathrm{TiO}_{2}$ for fabrication of solar cell because $\mathrm{PC}_{71} \mathrm{BM}$ gives improved spectral response in visible region than $\mathrm{PC}_{61} \mathrm{BM}$. The cell efficiency was increased by the insertion of $\mathrm{TiO}_{2}$. Higher value of $\mathrm{J}_{\mathrm{sc}}$ and FF were due to red- shift due to efficient intermolecular $\pi-\pi$ stacking interactions giving better hole [59].

Youming Zhang and co-workers synthesized D-A-Ar-type dye $\mathbf{1 5}$ in which triphenylamine (TPA), diketopyrrolopyrrole (DPP) and phenanthrene (P) were used as the donor (D) core, acceptor (A) arm, and enlarged $\pi$-system of polycyclic arene (Ar) terminal gave efficiency of 
$3.42 \%$. The key to this increase was due to incorporating additional DPP-P arm unit into the small molecules which can further improve photovoltaic properties of its derivative molecules. Improvement in hole mobility is also exhibited when TPA-DPP is replaced by TPA-DPP-P or TPA (DPP-P)2 as donor in the optimized hole-only devices. The increasing hole mobility is responsible for the improved $\mathrm{FF}$ value in the optimized dye $15 / \mathrm{PC}_{71} \mathrm{BM}$ device $[60]$.

Acceptor-donor-acceptor (A-D-A) dye 16 with a central dithieno [3,2- b:2',3'-d]pyrrole unit and thieno[2,3-c]pyrrole-4,6-dione as end-capping groups was prepared by Lauren G. Mercier and co-worker. A thiophene spacer was incorporated to decrease HOMO-LUMO gap. The obtained overall efficiency for dye $16 / \mathrm{PC}_{71} \mathrm{BM}$ was $2.6 \%$ [61].

Ping Fang Xia and co-workers used Dye 17 with electron-donating triarylamino group and electron accepting tricyanovinyl group PhN-OFOT(n)-TCN in OSCs with efficiency of $1.33 \%$ were obtained. This was probably because of an increased absorption due to thermal annealing of oligothiophene thin films at $100{ }^{\circ} \mathrm{C}$ resulting in reduction of device series resistance. Another reason for efficiency was tricyanovinyl group is highly efficient to decrease LUMO level and reduce the optical energy gap of a p-type photosensitizer [62].

Weifeng Zhang and co-workers report synthesis and donor-acceptor oligothiophenes PhNOF-OT (n)-DCN and G2-OT (n)-DCN where $\mathrm{n}=5,6$. Amongst them triarylamine and dicyanovinyl asymmetrically disubstituted oligothiophenes 18 (PhNOF-OT (5)-DCN) gave more efficiency compare to other. The results were concluded that oligomers with extended donor-acceptor can be suitable as p-type low bandgap semiconductor [63].

W. Porzio et al. proposed oligomers with different joining of thiophene $(\mathrm{T})$ and fluorenone (F) units and proposed their effect on chemical, electrochemical and optical properties of the materials. Dye 19/PCBM has resulted in efficiency of $0.77 \%$ [64]. 
Dye 20 comprising anthracene-core donor molecules with acetylenic spacers with better efficiency than the donor molecule ontaining olefinic spacer [65].

By Wallace W. H. Wong gave synthesis of 9,9-dioctylfluorenyl hexa-perihexabenzocoronene (FHBC) cores (Dye 21). Here authors have highlighted the molecular organization importance towards OSCs performance [66].

Derivatives of borondipyrromethene (BODIPYs) resulted in different fluorescent dyes that have attracted substantial attention in recent years. Theodulf Rousseau and co-workers report 1.34\% efficiency for BODIPY derivatives as donor and PCBM as acceptor. Dye 22 showed $44 \% \mathrm{FF}$ due to the more extended $\pi$-conjugated structure which leads to better hole-transport properties or better charge collection at the electrodes [67].

merocyanine (MC) having low molecular weight as p-type component with PCBM as acceptor resulted $1.74 \%$ efficiency which may be attributed to tunable properties of MC dyes such as redox, absorption, film forming and packing [69].

The phenothiazine dyes comprise sulfur and nitrogen atoms with non-planar geometry. Aaron S. Hart and co-workers studied the effect of cyanoacrylic acid anchoring group position on ring periphery of phenothiazine dye towards DSSCs. $4.07 \%$ efficiency of dye $\mathbf{2 5}$ resulted due to wider spectral range, highly fluorescent, harder oxidation potential, low excited state energy [70].

A sequence of oligothiophene derivatives with cyanoacrylic acid group was prepared with conjugation length from one to five thiophene units by Miquel Planells and co-workers. As the thiophene chain length increases from one to five thiophene units lowers LUMO energies together with energy gap. Dye 26 with four thiophene units gave higher efficiency of $2.32 \%$. This was may be possible because of number of thiophene units, if it lower or higher than three or four results in an energetic barrier for the charge extraction at the $\mathrm{TiO}_{2} /$ oligothiophene/ $\mathrm{P}_{3} \mathrm{HT}$ interface [71]. 
Kwangseok Do and co-workers used D-A-D-A-D type molecule toward BHJ solar cells resulting efficiency of $5.69 \%$ which may be attributed to low ratio of electron and hole mobility [72].

Yafei Wang co-workers obtained an overall efficiency of $4.38 \%$ for D- $\pi$-A- $\pi$-A based dye $\mathbf{2 8}$ containing 5-Phenyl-5Hdibenzo-[b,f]azepine (PDBAz) derivatives (donor), thiophene ( $\pi$ bridge) and isoindigo and cyanoacrylic acid (acceptors). Dye $\mathbf{2 8}$ showed red-shifted absorption contributed by conjugation extention and increased donor ability than the bisPDBA-aniline derivative [73].

Prashant Sonar and co-workers reported synthesis of low bandgap diketopyrrolopyrrole (DPP) derivatives with trifluoromethylphenyl as electron withdrawing groups and trifluorophenyl as acceptor in OSCs. The efficiency of $1.00 \%$ was may be due to DPP moiety which can be utilised as a capable building block for preparation of low bandgap acceptors [76].

Recently again Prashant Sonar and co-workers were study Dye 32 (AS-2) with triphenylamine as donor, 1,4-phenylenediacetonitrile as acceptor and a thiophene ring as $\pi$ bridge. Thin film of AS-2 showed an enriched light-harvesting ability, increase in wavelength, narrower optical band-gap. Efficiency of $4.10 \%$ may be due to extended molecular conjugation of thiophene functionality of AS-2 [77].

$\mathrm{N}$-functionalized pyrrole-based organic dyes were designed and synthesized by Huiyang Li and co-worker. Dye $\mathbf{3 3}$ was consisting cyanoacetic acid moieties as acceptor, triphenylamine as donor. To decrease the aggregation of dyes on surface of $\mathrm{TiO}_{2}$, an electron-withdrawing group pentafluorophenyl was linked to the nitrogen atom of the pyrrole ring. It also enhances the photo-stability of the pyrrole-based dyes and the light-harvesting abilities [78]. 
Triphenylamine-based organic dyes with different electron acceptors were prepared as sensitizers for DSSCs. Among different electron acceptors, cyanoacrylic acid electron acceptor gave highest efficiency of $4.93 \%[\mathbf{8 0}]$.

Metal-free organic dye 36 containing thienylethynyl as spacer was synthesized by Manal AlEid and co-workers for DSSCs. $4.49 \%$ efficiency of dye 36 indicated that as thiophene unit and length of conjugated spacer increases, the oxidation, reduction potential and subsequently band gap of the molecule decreases as compared to other dyes mentioned by Manal Al-Eid and co-workers $[\mathbf{8 1}]$.

Prashant Sonar with William Kylberg and co-workers again worked on the Diketopyrrolopyrrole (DPP)-based organic semiconductors. Dye 37 EH-DPP-TFPV containing branched ethyl-hexyl solubilizing alkyl chains and trifluoromethyl phenyl groups as end cap. This dye $\mathbf{3 7}$ was used in bilayer OPV devices with fullerenes as acceptors with PCE of $3.3 \%[82]$.

Recently, in our work we report synthesized and utilized D-D-A-type molecules containing enlarged linkers towards OSCs and studied co-adsorbent effect. We observed that cholic acid increases efficiency, whereas dodecylamine shows reverse effect [83].

Highly stable, solution-processable phenothiazine phenothiazine, 4-phenothiazin-10-ylanisole (APS) derivative (dye 40) as a hole collection material for Organic Solar Cells was reported by Jen-Hsien Huang and co-workers. This dye $\mathbf{4 0}$ gave PCE of 3.56\% as it is highly stable to enhance the stability of OSCs and was good optical and electronic properties [85].

Star shape triphenylamine derivatized containing different combinations of thienylenevinylene branches with indanedione or dicyanovinyl groups were study by Sophie Roquet and co-workers. Optical and electrochemical studies reveled that data electronacceptor groups in the donor gives increase in oxidation potential. Synergistic effects of 
extended photoresponse and increased open-circuit voltage for dye $\mathbf{4 1}$ gave power conversion efficiency up to $1.17 \%[\mathbf{8 6}]$.

Dyes with pyridine as anchoring group with different nitrogen-based heterocyclic units linked through benzothiadiazole were prepared by M.N.K. Prasad Bolisetty and co-workers. The dye 42 gave $1.97 \%$ power conversion efficiency which may be attributed to its red shifted absorption spectra [87].

Changjian Zhong and co-workers were synthesized and reported triarylamine-based dyes with $\pi$-conjugated bridge containing thienyl, bithienyl or thiophene-phenyl and cyanoacetic acid as acceptor in DSSCs. Dye 43 with thiophene shows highest molar absorption coefficient. Authors stated that as $\pi$-conjugation increases, distance between the electron donor and acceptor increases which reduces charge recombination between the oxidized sensitizer and injected electrons in $\mathrm{TiO}_{2}$ conduction band leads to higher Voc [88].

Jie Liu and co-workers reported synthesis and application of D- $\pi$-A type dye with a dithienosilole conjucation, carbazole as electron donor and cyanoacrylic acid unit as electron acceptor in DSSCs. The power conversion efficiency of $4.80 \%$ was due to to the incorporation of DODTS (4,4-dioctyl dithienosilole) unit and may be attributed to the conjugation broadening [90].

Two co-adsorbents, 4-(bis(9,9- dimethyl-9H-flouren-2-yl)amino)-1-naphthoic acid (HCA4) and 4-(10-(bis(9,9-dimethyl-9H-flouren-2-yl)amino) anthracen-9-yl)benzoic acid (HCA5), were prepared and used in DSSCs using porphyrin as dye by Taek Choi and co-workers. HCA4 based DSSCs exhibited superior charge resistance, extended electron lifetime and a better IPCE compared to other co-adsobent [91].

D- $\pi$-A carbazole molecules containing $\pi$-bridge of 4-phenyl-2-(thiophen-2-yl) thiazole was synthesized and reported by Ting $\mathrm{Li}$ and co-workers. It was observed that the $\pi$-bridge links 
at the benzene ring instead of the $\mathrm{N}$ atom of the carbazole donor unit of molecule shows better results [92].

6H-Indolo[2,3-b]quinoxaline-based organic dyes comprising different conjugated linkers like oligothiophene, thienyl carbazole, and furyl carbazole were synthesized by Xing Qian and coworkers. Dye 48 with oligothiophene $\pi$-linker revealed a broad region up to about $770 \mathrm{~nm}$ covering good visible light range and gave an efficiency of $7.62 \%$ [93].

Po-Yu Ho and co-workers gave synthesis of D- $\pi$-A organic photosensitizers based on triarylamine donor and selenophene $\pi$-linker for DSSCs. They conclude that starburst electron donor design can minimize dye aggregation on $\mathrm{TiO}_{2}[\mathbf{9 4}]$.

Akhil Gupta and co-workers used 4-(cyanomethyl) benzoic acid as an acceptor group in DSSCs and compare it with cyanoacrylic acid acceptor with replacement of the bridging para-phenyl group in the triaryl donor with a thiophene group. It improves efficiency of device upto $6.37 \%[95]$.

Dyes with pyrenoimidazole donors, oligothiophene $\pi$-linkers and cyanoacrylic acid acceptors were reported by Dhirendra Kumar and co-workers. Results stated that as donor capacity of pyrenoimidazole and oligothiophene $\pi$-linkers increases, significant improvement in overall efficiencies of DSSCs can be achieved [96].

Fei $\mathrm{Wu}$ prepared three $\mathrm{D}-\pi-\mathrm{A}$ type dyes composed of diarylmethylene-bridged triphenylamine (electron donor), thiophene ( $\pi$-spacer) and cynoarylic acid (electron acceptor) with $4.35 \%$ efficiency [97].

Ooyama et al. suggested that the (D) $2-\pi-$ A BODIPY structure with two diphenylaminethienylcarbazole moieties as strong electron-donating units at the 3- and 5-positions on the BODIPY is an effective strategy to lead a high light-harvesting efficiency (LHE) in the range of visible light to NIR light [100]. 
Recently, series of fused-ring electron acceptors with different side chains as $\pi$ bridge were prepared and applied in non-fullerene OSCs with maximum average efficiency of $6.9 \%$ [101]

A-D-A type molecule based on dioctyltertthiophene-benzo[1,2-b:4,5-b']dithiophenedioctyltertthiophene central donor and vinazene terminal acceptor was synthesised and systematically used for BHJ solar cell by grouping thermal annealing and solvent vapor annealing treatments, with an optimized PCE of 3.73\% [102].

The dye QX23 with a furan $\pi$-bridge and a cyanoacrylic acid acceptor/anchoring group was reported a good PCE of 7.09\% indicating it is a promising dye to construct DSSC [103].

Zhao DX et al. have developed a 3D triphenylamine moiety as electron donor group to solve the issues of dye aggregation, dark current and charge recombination in DSSCs and achieved efficiency of $4.333 \%$ with NUIST1 dye [104].

$\mathrm{A}_{1}-\mathrm{A}-\mathrm{A}_{1}$ type small molecules were synthesized by incorporating the benzothiadiazole and diketopyrrolopyrrole units $(\mathrm{A})$ and naphthalimide units $\left(\mathrm{A}_{1}\right)$ in the molecular backbone and non-fullerene BHJ-OSCs were obtained with PCE values of $1.23 \%$ and $1.64 \%$ by utilizing NI-BT and NI-DPP as acceptors and PTB7-Th as the donor [105].

A series of push-pull organic dyes incorporating a cyanoacrylic acid group (electron acceptor) and $\alpha$-chalcogenopyranylidene group $(\mathrm{X}=\mathrm{S} ; \mathrm{O})$ (electron donor) has been prepared by Ferreira et al. with maximum efficiency of $2.03 \%[\mathbf{1 0 6}]$.

\section{Recent Improvement in Electrolytes Used in Solar Cell}

The electrolyte plays major role in OSCs and DSSCs as it shows large effect on efficiency and stability of solar cell. As soon as light pass in to cell, it expels electron from the donor layer and then this electron enters the acceptor material layer and diffuses to an electrode. The main function of electrolyte is to provide electrons back to the dye for its regeneration [28]. The most efficient electrolyte that has been used in solar is based on an iodide/triiodide 
couple. Another type of electrolytes such as ionic liquids has been also used in solar cells. Some of the reported electrolytes has been discussed as foolows:

A liquid electrolyte used in dye $\mathbf{1}$ consisting of 3-propyl-1-methyl-imidazolium iodide (PMII, $1 \mathrm{M})$, lithium iodide (LiI, $0.2 \mathrm{M})$, iodide $\left(\mathrm{I}_{2}, 0.05 \mathrm{M}\right)$, and tert-butylpyridine (TBP, $\left.0.5 \mathrm{M}\right)$ in acetonitrile/valeronitrile $(85: 15)$ has been reported with efficiency of $7.3 \%$ [46].

Organic dye 2 uses electrolyte made from 0.1 M LiI, 0.05 M I2, 0.6 M PMII, 0.5 M TBP in the mixed solvent of acetonitrile and MPN (7:3, v/v) with efficiency of $6.68 \%$ [47].

Synthesis and fabrication substituted benzimidazole organic dye $\mathbf{5}$ has been reported using 0.5 M LiI, 0.05 M iodine ( $\mathrm{I}_{2}$ ) and 0.5 M 4-tert-butylpyridine (TBP) in 3-methoxypropionitrile with efficiency of $3.47 \%$ [50].

Synthesis of two different imidazole derivatives to the structure of triphenylamine, and the 2cyanoacetic acid acts as acceptor group to prepare two 2D- $\pi$-A dyes has been reported by Ximing Chen and co-workers. The electrolyte used was $0.6 \mathrm{M}$ 1,2-dimethyl-3propylimidazolium iodide (DMPII), 0.0653M LiI, 0.03M I2, 0.28M 4-tertbutylpyridine (TBP) and $0.05 \mathrm{M}$ guanidium thiocyanate $(\mathrm{GuSCN})$ in acetonitrile with efficiency as $4.11 \%$ [56]. The photovoltaic performances of two dyes were assessed in DSSCs based the electrolyte consists of $0.05 \mathrm{M} \mathrm{I}_{2}, 0.05 \mathrm{M} \mathrm{LiI}, 0.5 \mathrm{M}$ BMII, 0.1 M DMPII and 0.1 M GuSCN in acetonitrile with overall efficiency of $4.38 \%$ [73].

Electrolyte composed of 0.1 M lithium bis(tri-uoromethylsulfonyl)imide (LiTFSI) and $0.5 \mathrm{M}$ 4-tert-butylpyridine (TBP) in acetonitrile gave efficiency of $10.7 \%$ [75].

Huiyang $\mathrm{Li}$ and co-workers used electrolyte containing $0.1 \mathrm{M}$ lithium iodide, $0.6 \mathrm{M}$ butylmethylimidazolium iodide (BMII), 0.05 $\mathrm{M} \mathrm{I}_{2}$ and $0.5 \mathrm{M}$ 4-tert-butylpyridine (4-TBP) in the mixed solvent of acetonitrile and 3-methoxypropionitrile $(7: 3, \mathrm{v} / \mathrm{v})[\mathbf{7 8}]$.

The organic electrolyte for DSSCs has been used by Xiaoqiang $\mathrm{Yu}$ and co-workers containing 0.06 M LiI, 0.03 M I2, 0.1 M guanidinium thiocyanate, 0.6 M 1-propyl-3- 
methylimidazolium iodide (PMII), and 0.5 M tert-butyl-pyridine in acetonitrile. Efficiency of $4.93 \%$, short-circuit photocurrent density $\mathrm{Jsc}=8.59 \mathrm{~mA} / \mathrm{cm}^{2}$, open-circuit photovoltage Voc $=0.77 \mathrm{~V}$, and fill factor $\mathrm{ff}=0.75$ under $100 \mathrm{~mW} / \mathrm{cm}^{2}$ simulated AM $1.5 \mathrm{G}$ solar irradiation was reported $[\mathbf{8 0}]$.

An ionic liquid electrolyte (0.60 M butylmethylimidazolium iodide (BMIM-I), $0.03 \mathrm{M} \mathrm{I}$, $0.50 \mathrm{M}$ 4-tertbutylpyridine (TBP) and $0.10 \mathrm{M}$ guanidinium thiocyanate (GTC) in acetonitrile/valeronitrile $85 / 15(\mathrm{v} / \mathrm{v})$ was used for dye 36 providing efficiency of $4.49 \%$ [81]. The electrolyte composition (electrolyte 1): $0.6 \mathrm{M}$ dimethylpropylimidazolium iodide (DMPII), 0.05 M I2, 0.1 M LiI, and 0.5 M tert-butylpyridine (TBP) in acetonitrile has been reported in dye sensitized solar cell for dye 39 [84].

M. N. K. Prasad Bolisetty and co-workers used electrolyte made up of mixture of 0.1M LiI, 0.6 M DMPII, 0.05 M I2, and 0.5 M TBP in 3-methoxypropionitrile/ACN (volume ratio 1:1) $[85]$.

The synthesis of dye $\mathbf{4 3}$ was reported with efficiency of $6.24 \%$. The electrolyte used for this was mixture of $\mathrm{CH}_{3} \mathrm{CN}$ solution of $0.3 \mathrm{M}$ 1-methyl-3- propylimidazolium iodide (MPII), 0.03 $\mathrm{M} \mathrm{I}_{2}, 0.07 \mathrm{M}$ LiI, 0.1 M guandine thiocyanate and 0.4 M 4-tert-butylpyridine (TBP) [88]. Electrolyte composition: 0.6 MDMPII, 0.5 MTBP, 0.05 $\mathrm{MI}_{2}$ and $0.1 \mathrm{MLiI}$ in $\mathrm{CH}_{3} \mathrm{CN}$ has been used for dye $\mathbf{4 6}$ achieved a PCE of 7.7\% [91].

D- $\pi$-A carbazole molecule gave efficiency of $4.72 \%$. The electrolyte used for this was composed of the $\mathrm{CH}_{3} \mathrm{CN}$ solution of $0.3 \mathrm{M}$ 1-methyl-3-propylimidazolium iodide (MPII), 0.03M I2, 0.07M LiI, 0.1M guandine thiocyanate and 0.4M 4-tert-butylpyridine (TBP) [92]. Xing Qian and co-worker synthesized novel organic dye $\mathbf{4 8}$ using electrolyte composed of 0.3M DMPII, 0.1M LiI, 0.05MI2, and 0.5M 4-tertbutyl pyridine in acetonitrile [93].

New D- $\pi$-A organic dye 49 was synthesized and applied as DSSCs with efficiency of $7.91 \%$. The electrolyte used for dye 49 was composed of $0.1 \mathrm{M}$ LiI, $0.6 \mathrm{M}$ 1,2-dimethyl-3- 
propylimidazolium iodide (DMPII), $0.05 \mathrm{M} \mathrm{I}_{2}$ in a mixture of acetonitrile and 4-tertbutylpyridine (volume ratio, 1:1) [94].

Akhil Gupta and co-workers used nitrile-based and ionic liquid-based electrolytes containing 1.0 M 1,3-dimethylimidazolium iodide, $0.03 \mathrm{M}$ iodine, $0.1 \mathrm{M}$ guanidinium thiocyanate, 0.5 $\mathrm{M}$ tert-butylpyridine, $0.05 \mathrm{M}$ lithium iodide in a mixture of acetonitrile/valeronitrile $(85 / 15$, v/v) and 1-ethyl-3-methylimidazolium iodide/1,3- dimethylimidazolium iodide/1-ethyl-3methylimidazolium tetracyanoborate/ lithium iodide/Iodine/ N-methylbenzimidazole in molar ratio (12:12:16:1:1.67:4) respectively [95].

The electrolyte used for dye 55 was consist of $0.8 \mathrm{M} \mathrm{PMII} / 0.05 \mathrm{M} \mathrm{I} / 2.0 .10 \mathrm{M} \mathrm{LiI} / 0.5 \mathrm{M}$ tertbutylpyridine in acetonitrile solution gives the power conversion efficiency of $7.53 \%$ [99].

\section{Summery and Future Aspects}

Last year was the fruitgainer for the research area of OSCs as we able to cross the benchmark efficiency of $10 \%$ for OSCs. Yan $\mathrm{H}$ et al reported efficiency of $11.7 \%$ processed from hydrocarbon solvents [107]. Phillips 66 (NYSE: PSX) has successfully achieved efficiency of 11.84\% [108]. Also Heliatek R\&D team came up with 13.2\% efficiency, setting up new world record for OSCs [109].

Betterment of mankind is largely depended on sustainable civilization. This can be achieved only if we tried to focus on utilising natural resources to fulfil our energy requirements. Therefore, if we closely look towards till date developments in energy harvesting field, indirectly we are trying to mimic nature, which is good sign for mankind. Because natural processes are most efficient and search for better and better transport layers in OSCs and DSSCs will be motivated by this point only. If we try to lined up our research by keeping natural energy harvesting processes as standard one, we can achieve most safer and better alternative for the energy needs of mankind. As stated in objectives, first we need to find where we are standing now and by reviewing ongoing research where we can land up. 
Therefore, in this article we tried to focus on designing of organic molecules by different combinations of donors, acceptors and linkers with smooth transport capacity for excitons.

Over the last 10 years' scientist designed and synthesized different OSCs and DSSCs which were assimilated in this review. Mainly, this review is based on the basic terminologies used in organic solar cell. For the fabrication of solar cell different donor and acceptor materials are used and they were fabricated by different ways which were presented here. There are many factors which affect efficiency of OSCs and DSSCs, mainly structure of molecule, function and molecule to molecule interaction. Another way to improve the efficiency of solar cell are electrolytes used in cell and addition of co-adsorbents which can prevent $\pi-\pi$ stacking or aggregation of dyes. Considering all these factors, it is possible to design and synthesize novel molecules for efficient working in OSCs and DSSCs which is the main aim behind compiling this review.

This review will be helpful to the organic chemist to assess and formulate necessary parameters for the fabrication of OSCs and DSSCs. Different types of compounds which have incorporated in this review can be considered as base for developing more efficient OSCs and thinking over the findings of different studies of different organic molecules towards their behaviour in the field of OSCs it is possible to device and fabricate newer and better organic molecules in future. There are number of factors used for the determination of fill factor and efficiency of solar cells which are necessary to know for the researchers and this review article will be a path finder for organic chemistry researchers in search of better organic molecules for OSCs. 


\section{Acknowledgement}

One of the Authors (PPK) acknowledge UGC, New Delhi for SAP (DSA-I) fellowship under the scheme 'Research Fellowship in Sciences for Meritorious Students'. P. M. S is thankful to QUT for the financial support from QUT core funding (QUT/ 322120-0301/07). P. M. S also acknowledges to the Australian Research Council (ARC) for the Future Fellowship (FT130101337). 


\section{References}

[1] Huang JH, Lee KC. Highly Stable, Solution-processable phenothiazine derivative as hole collection material for organic solar cells. ACS Appl Mater Interfaces 2014; 6: $7680-5$.

[2] Xie K, Guob M, Huang H. Photonic crystals for sensitized solar cells: fabrication, properties, and applications. J Mater Chem C 2015; 3: 10665-86.

[3] Yoon TP, Ischay MA, Du J. Visible light photocatalysis as a greener approach to photochemical synthesis. Nat Chem 2010; 2: 527-32.

[4] Mishra A, Fischer MKR, Bauerle P. Metal-Free Organic dyes for dye-sensitized solar cells: from structure: property relationships to design rules. Angew Chem Int ed. 2009; 48:2474-99.

[5] Silvestri F, Marrocchi A, Seri M, Kim C, Marks TJ, Facchetti A, Taticchi A. Solution-processable low-molecular weight extended arylacetylenes: versatile p-type semiconductors for field-effect transistors and bulk heterojunction solar cells. J Am Chem Soc 2010; 132:6108-23.

[6] Irwin MD, Servaites JD, Buchholz DB, Leever BJ, Liu J, Emery JD, et al. Structural and electrical functionality of nio interfacial films in bulk heterojunction organic solar cells. Chem Mater 2011; 23:2218-26.

[7] Li YS, Tsai CH, Kao SH, Wu IW, Chen JZ, Wu CI, et al. Single layer organicinorganic-hybrid thin film encapsulation for organic solar cell. J Phys D: Appl Phys $2013 ; 46: 435502$.

[8] Jaina V, Rajbongshi BK, Mallajosyulaa AT, Bhattacharjya G, Iyera SSK, Ramanathan G. Photovoltaic effect in single-layer organic solar cell devices fabricated with two new imidazolin-5-one molecules. Sol. Energy Mater. Sol. Cells. 2008, 92; 9:1043-6. 
[9] Jo J, Pouliot JR, Wynands D, Collins SD, Kim JY, Nguyen TL et at. Enhanced efficiency of single and tandem organic solar cells incorporating a diketopyrrolopyrrole-based low-bandgap polymer by utilizing combined $\mathrm{ZnO}$ /polyelectrolyte electron-transport layers. Adv Mater 2013; 25:4783-8.

[10] Chamberlain GA. Organic solar cells: A review. Solar Cells 1983; 8:47-83.

[11] Wohrle D, Meissner D. Organic solar cells. Adv Mater 1991; 3: 129-38.

[12] Kim H, Nam S, Jeong J, Lee S, Seo J, Han H, et al. Organic solar cells based on conjugated polymers: history and recent advances. J Chem Eng 2014; 31:1095-1104.

[13] Kolesov VA, Fuentes-Hernandez C, Chou WF, Aizawa N, Larrain FA, Wang M, Perrotta A, Choi S, Graham S, Bazan GC, Nguyen TQ, Marder SR, Kippelen B. Solution-based electrical doping of semiconducting polymer films over a limited depth. Nat Mater 2017; 16:474-480.

[14] Gunes S, Neugebauer H, Sariciftc NS. Conjugated polymer-based organic solar cells. Chem Rev 2007; 107:1324-1338.

[15] Lee JH, Sagawa T, Takafujia M, Ihara H. Modeling of optimum size and shape for high photovoltaic performance of poly(3-hexylthiophene) nanopore in interdigitated bilayer organic solar cells. Org Electron 2016; 28:59-66.

[16] Gommans BH, Aernouts T, Verreet B, Heremans P, Medina A, Claessens CG, et al. Perfluorinated Subphthalocyanine as a new acceptor material in a small-molecule bilayer organic solar cell. Adv Funct Mater 2009; 19: 3435-9.

[17] Eisenmenger ND, Delaney KT, Ganesan V, Fredrickson GH, Chabiny ML. Energy transfer directly to bilayer interfaces to improve exciton collection in organic photovoltaics. J Phys Chem C 2015; 119:19011-21. 
[18] Seok J, Shin TJ, Park S, Cho C, Lee JY, Ryu DY, et al. Efficient organic photovoltaics utilizing nanoscale heterojunctions in sequentially deposited polymer/ fullerene bilayer. Sci Rep 2015; 5: 8373.

[19] Casalegno M, Carbonera C, Luzzati S, Raos G. Coarse-grained kinetic modelling of bilayer heterojunction organic solar cells. Org Electron 2012; 13: 750-61.

[20] Wanga L, Hinderling C, Jenatscha S, Nuescha F, Zhang DRRS, Hany R. Cyanine dye polyelectrolytes for organic bilayer solar cells. Polymer 2014; 55: 3195-3201.

[21] Wicht G, Bucheler S, Dietrich M, Jager T, F Nuesch, Offermans T. Stability of bilayer trimethine cyanine dye/fullerene organic solar cells. Sol Energy Mater Sol Cells 2013; 117: 585-91.

[22] Ahna S, Janga W, Parkb JH, Wang DH. Enhanced performance of layer-evolved bulk-heterojunction solar cells with Ag nanoparticles by sequential deposition. Org Electron $2015 ; 24: 325-29$.

[23] Choi WT, Song J, Ko J, Jang Y, Kim TH, Han YS, et al. Effect of solvent additives on bulk heterojunction morphology of organic photovoltaics and their impact on device performance. J Polym Sci, Part B: Polym Phys 2016; 54:128-134.

[24] Nardes AM, Ferguson AJ, Wolfer P, Gui K, Burn PL, Meredith P, et al. Free Carrier Generation in Organic Photovoltaic Bulk Heterojunctions of Conjugated Polymers with Molecular Acceptors: Planar versus Spherical Acceptors. Chem Phys Chem $2014 ; 15: 1539-49$.

[25] Zhang G, Huber RC, Ferreira AS, Boyd SD, Luscombe CK, Tolbert SH, et al. Crystallinity Effects in Sequentially Processed and Blend-Cast Bulk-Heterojunction Polymer/Fullerene Photovoltaics. J Phys Chem C 2014; 118: 18424-35.

[26] Hoppe H, Sariciftci NS. Organic solar cells: An overview. J Mater Res 2004; 19: 1924-45. 
[27] Shi Y, Tan L, Chen L, Chen Y. Alternative alcohol-soluble conjugated small molecule electrolytes for high-efficiency inverted polymer solar cells. Phys Chem Chem Phys 2015; 17:3637-46.

[28] Wang M, Chamberland N, Breau L, Moser JE, Baker RH, Marsan B, et al. An organic redox electrolyte to rival triiodide/iodide in dye-sensitized solar cells. Nat Chem $2010 ; 2: 385-9$.

[29] Jin MJ, Jo J, Kim JH, An KS, Jeong MS, Kim J, et al. Effects of $\mathrm{TiO}_{2}$ Interfacial Atomic Layers on Device Performances and Exciton Dynamics in ZnO Nanorod Polymer Solar Cells. ACS Appl Mater Interfaces 2014; 6: 11649-56.

[30] Smijs TG, Pavel S. Titanium dioxide and zinc oxide nanoparticles in sunscreens: focus on their safety and effectiveness. Nanotechnol Sci Appl 2011; 4: 95-112.

[31] Tian J, Zhao Z, Kumar A, Boughton RI, Liu H. Recent progress in design, synthesis, and applications of one-dimensional $\mathrm{TiO}_{2}$ nanostructured surface heterostructures: $\mathrm{A}$ review. Chem Soc Rev 2014; 43:6920-37.

[32] Wang S, Zhao L, Bai L, Yan J, Jiang Q, Lian J. Enhancing photocatalytic activity of disorderengineered $\mathrm{C} / \mathrm{TiO}_{2}$ and $\mathrm{TiO}_{2}$ nanoparticles. J Mater Chem A 2014; 2:7439-45.

[33] Wang M, Ioccozia J, Sun L, Lin C, Lin Z. Inorganic-modified semiconductor $\mathrm{TiO}_{2}$ nanotube arrays for photocatalysis. Energy Environ Sci 2014;7: 2182-202.

[34] Park OK, Kang YS. Preparation and characterization of silica-coated $\mathrm{TiO}_{2}$ nanoparticle. Colloids Surf., A 2005; 257-258: 261-5.

[35] Zhang Q, Gao L. One-step preparation of size-defined aggregates of $\mathrm{TiO}_{2}$ nanocrystals with tuning of their phase and composition. J Eur Ceram Soc 2006; $26: 1535-45$.

[36] Huang X, Pan C. Large-scale synthesis of single-crystalline rutile $\mathrm{TiO}_{2}$ nanorods via a one-step solution route. J Cryst Growth 2007; 306: 117-22. 
[37] Wang X, Wu G, Zhou B, Shen J. Optical constants of crystallized $\mathrm{TiO}_{2}$ coatings prepared by sol-gel process. Materials 2013; 6: 2819-30.

[38] Apostoluk A, Zhu Y, Canut B, Masenelli B, Delaunay JJ, Znajdek K, et al. Investigation of luminescent properties of $\mathrm{ZnO}$ nanoparticles for their use as a downshifting layer on solar cells. Phys Status Solidi C 2013; 10: 1301-7.

[39] Vittal R, Ho KC. Zinc oxide based dye-sensitized solar cells: A review. Renewable Sustainable Energy Rev 2017; 70: 920-35.

[40] $\mathrm{Xu} \mathrm{S}$, Wang ZL. One-dimensional $\mathrm{ZnO}$ nanostructures: solution growth and functional properties. Nano Res 2011; 4:1013-98.

[41] Cowan SR, Schulz P, Giordano AJ, Garcia A, MacLeod BA, Marder SR, et al. Chemically controlled reversible and irreversible extraction barriers via stable interface modified cation of zinc oxide electron collection layer in polycarbazolebased organic solar cells. Adv Funct Mater 2014; 24:4671-80.

[42] Eom SH, Baek MJ, Park H, Yan L, Liu S, You W, et al. Roles of interfacial modifiers in hybrid solar cells: inorganic/polymer bilayer vs inorganic/polymer:fullerene bulk heterojunction. ACS Appl Mater Interfaces 2014; 6:803-10.

[43] Pradhan B, Albrecht S, Stiller B, Neher D. Inverted organic solar cells comprising low-temperature-processed ZnO films. Appl Phys A 2014; 115:365-9.

[44] Ho PY, Thiyagu S, Kao SH, Kaoa CY, Lin CF. ZnO nanorod arrays for various lowbandgap polymers in inverted organic solar cells. Nanoscale 2014; 6:466-71.

[45] Baviskar PK, Zhang JB, Gupta V, Chand S, Sankapal BR. Nanobeads of zinc oxide with rhodamine B dye as a sensitizer for dye sensitized solar cell application. J Alloys Compd 2012; 510:33-7. 
[46] Jo HJ, Nam JE, Kim DH, Kim H, Kang JK. A comparison of the electronic and photovoltaic properties of novel twin-anchoring organic dyes containing varying lengths of $\pi$-bridges in dye-sensitized solar cells. Dyes Pigm 2014; 102: 285-92.

[47] He J, Hua J, Hu G, Yin XJ, Gong H, Li C. Organic dyes incorporating a thiophene or furan moiety for efficient dye-sensitized solar cells. Dyes Pigm 2014; 104: 75-82.

[48] Colella S, Mazzeo M, Grisorio R, Fabiano E, Melcarne G, Carallo S, et al. Monodispersed molecular donors for bulk hetero-junction solar cells: from molecular properties to device performances. Chem Commun 2010; 46:6273-5.

[49] Choi H, Paek S, Song J, Kim C, Cho N, Ko J. Synthesis of annulated thiophene perylene bisimide analogues: their applications to bulk heterojunction organic solar cells. Chem Commun 2011; 47:5509-11.

[50] Manoharan S, Anandan S. Cyanovinyl substituted benzimidazole based (D- $\pi-A)$ organic dyes for fabrication of dye sensitized solar cells. Dyes Pigm 2014; 105: 223 31.

[51] Chen Y, Du Z, Chen W, Liu Q, Sun L, Sun M, et al. Benzo[1,2-b:4,5-b']dithiophene and benzotriazole based small molecule for solution-processed organic solar cells. Org. Electron 2014; 15:405-13.

[52] Silvestri F, Marrocchi A, Seri M, Kim C, Marks TJ, Facchetti A, Taticchi A. Solution-processable low-molecular weight extended arylacetylenes: versatile p-type semiconductors for field-effect transistors and bulk heterojunction solar cells. J Am Chem Soc 2010; 132:6108-23.

[53] Kwon J, Lee W, Kim JY, Noh S, Lee C, Hong JI. Solution processable donor materials based on thiophene and triphenylamine for bulk heterojunction solar cells. New J Chem 2010; 34: 744-9. 
[54] Wanga L, Yin L, Ji C, Zhang Y, Gao H, Li Y. High open-circuit voltage of the solution-processed organic solar cells based on benzothiadiazole-triphenylamine small molecules incorporating $\pi$-linkage. Org Electron $2014 ; 15: 1138-48$.

[55] Zhou R, Li QD, Li XC, Lu SM, Wang LP, Zhang CH, et al. A solution-processable diketopyrrolopyrrole dye molecule with (fluoronaphthyl) thienyl end groups for organic solar cells. Dyes Pigm 2014; 101:51-7.

[56] Chen X, Jia C, Wan Z, Yao X. Organic dyes with imidazole derivatives as auxiliary donors for dye-sensitized solar cells: Experimental and theoretical investigation. Dyes Pigm 2014; 10:448-56.

[57] Cho MJ, Seo J, Oh HS, Jee HS, Kim WJ, Kim KH, et al. Tricyanofuran-based donoracceptor type chromophores for bulk heterojunction organic solar cells. Sol Energy Mater Sol Cells 2012; 98:71-7.

[58] Kim J, Cho N, Ko HM, Kim C, Lee JK, Ko J. Push-pull organic semiconductors comprising of bis-dimethylfluorenyl amino benzo[b]thiophene donor and various acceptors for solution processed small molecule organic solar cells. Sol Energy Mater Sol Cells 2012;102: 159-66.

[59] Do K, Kim C, Song K, Yun SJ, KwanLee J, Ko J. Efficient planar organic semiconductors containing fused triphenylamine for solution processed small molecule organic solar cells. Sol Energy Mater Sol Cells 2013; 115:52-7.

[60] Zhang Y, Tan H, Xiao M, Bao X, Tao Q, Wang Y, et al. D-A-Ar type small molecules with enlarged $\pi$-system of phenanthrene at terminal for high-performance solution processed organic solar cells. Org Electron 2014; 15:1173-83.

[61] Mercier LG, Mishra A, Ishigaki Y, Henne F, Schulz G, Bauerle P. Acceptor-donor acceptor oligomers containing dithieno[3,2, $\mathrm{b}: 2,3$ [ $\mathrm{d}]$ pyrrole and 
Thieno[2,3]c]pyrrole-4,6-dione units for solution-processed organic solar cells. Org Lett $2014 ; 16: 2642-5$.

[62] Xia PF, Feng XJ, Lu J, Movileanu R, Tao Y, Baribeau JM, et al. Triarylamino and tricyanovinyl end-capped oligothiophenes with reduced optical gap for photovoltaic applications. J Phys Chem C 2008; 112:16714-20.

[63] Zhang W, Tse SC, Lu J, Tao Y, Wong MS. Solution processable donor-acceptor oligothiophenes for bulk-heterojunction solar cells. J Mater Chem 2010; 20:2182-9.

[64] Porzio W, Destri S, Pasini M, Giovanella U, Ragazzi M, Scavia G, et al. Synthesis and characterisation of fluorenone-thiophene-based donor-acceptor oligomers: role of moiety sequence upon packing and electronic properties. New J Chem 2010; 34:196173.

[65] Marrocchi A, Silvestri F, Seri M, Facchetti A, Taticchia A, Marks TJ. Conjugated anthracene derivatives as donor materials for bulk heterojunction solar cells: olefinic versus acetylenic spacers. Chem Commun 2009; 11:1380-2.

[66] Wong BWWH, Singh TB, Vak D, Pisula W, Yan C, Feng X, et al. Solution processable fluorenyl hexa-peri-hexabenzocoronenes in organic field-effect transistors and solar cells. Adv Funct Mater 2010; 20: 927-38.

[67] Rousseau T, Cravino A, Bura T, Ulrich G, Ziessel R, Roncali J. BODIPY derivatives as donor materials for bulk heterojunction solar cells. Chem Commun 2009; 13:16735.

[68] Mayerhoffer U, Deing K, Gruß K, Braunschweig H, Meerholz K, Wurthner F. Herausragende Kurzschlussstr_me in BHJ-Solarzellen auf Basis NIR-absorbierender, akzeptorsubstituierter Squaraine. Angew Chem 2009; 121:8934-7. 
[69] Kronenberg NM, Deppisch M, Wurthner F, Lademann HWA, Deing K, Meerholz K. Bulk heterojunction organic solar cells based on merocyanine colorants. Chem Commun 2008; 48:6489-91.

[70] Hart AS, Bikram KC, Subbaiyan NK, Karr PA, D’Souza F. Phenothiazine-sensitized organic solar cells: effect of dye anchor group positioning on the cell performance. ACS Appl Mater Interfaces 2012; 4:5813-20.

[71] Planells M, Abate A, Snaith HJ, Robertson N. Oligothiophene interlayer effect on photocurrent generation for hybrid $\mathrm{TiO}_{2} / \mathrm{P}_{3} \mathrm{HT}$ solar cells. ACS Appl Mater Interfaces $2014 ; 6: 17226-35$.

[72] Do K, Cho N, Siddiqui SA, Singh SP, Sharma GD, Ko J. New D-A-D-A-D push-pull organic semiconductors with different benzo[1,2-b:4, 5-b'] dithiophene cores for solution processed bulk heterojunction solar cells. Dyes Pigm 2015; 120:126-35.

[73] Wang Y, Yang C, Chen J, Qi H, Hua J, Liu Y, Baranoff E, Tan H, Fan J, Zhu W. Influence of the donor size in panchromatic $\mathrm{D}-\pi$-A- $\pi$-A dyes bearing 5-Phenyl5Hdibenzo-[b,f]azepine units for dye-sensitized solar cells. Dyes Pigm 2016; 127, 204-12.

[74] Nielsen CB, Holliday S, Chen HY, Cryer SJ, McCulloch I. Non-fullerene electron acceptors for use in organic solar cells. Acc Chem Res 2015; 48:2803-12.

[75] Wu H, Yang L, Li Y, Zhang M, Zhang J, Guo Y, et al. Unlocking the effects of ancillary electron-donors on light absorption and charge recombination in phenanthrocarbazole dye-sensitized solar cells. J Mater Chem A 2016; 4:519-28.

[76] Sonar P, Ng GM, Lin TT, Dodabalapur A, Chen ZK. Solution processable low bandgap diketopyrrolopyrrole (DPP) based derivatives: novel acceptors for organic solar cells J Mater Chem 2010; 20:3626-36. 
[77] Raynor AM, Gupta A, Plummer CM, Jackson SL, Bilic A, Patil H, et al. Significant improvement of optoelectronic and photovoltaic properties by incorporating thiophene in a solution-processable D-A-D modular chromophore. Molecules 2015; 20:21787-801.

[78] Li H, Yang L, Tang R, Hou Y, Yang Y, Wang H, et al. Organic dyes incorporating Nfunctionalized pyrrole as conjugated bridge for dye-sensitized solar cells: Convenient synthesis, additional withdrawing group on the $\pi$-bridge and the suppressed aggregation. Dyes Pigm 2013; 99: 863-870.

[79] Wu G, Kong F, Li J, Chen W, Fang X, Zhang C, et al. Influence of different acceptor groups in julolidine-based organic dye-sensitized solar cells. Dyes Pigm 2013; 99: $653-60$.

[80] Yu X, Ci Z, Liu T, Feng X, Wang C, Ma T, et al. New D-A-D-A-D pushepull organic semiconductors with different benzo[1,2-b:4, 5-b'] dithiophene cores for solution processed bulk heterojunction solar cells. Dyes Pigm 2014; 102: 126-32.

[81] Eid MA, Lim S, Park KW, Fitzpatrick B, Han CH, Kwak K, et al. Facile synthesis of metal-free organic dyes featuring a thienylethynyl spacer for dye sensitized solar cells. Dyes Pigm 104; 2014:197-203.

[82] Kylberg W, Sonar P, Heier J, Tisserant JN, Muller C, Nuesch F, et al. Synthesis, thinfilm morphology, and comparative study of bulk and bilayer heterojunction organic photovoltaic devices using soluble diketopyrrolopyrrole molecules. Energy Environ Sci $2011 ; 4: 3617-24$.

[83] Kumavat PP, Baviskar PK, Sankapal BR, Dalal DS. Synthesis of D-D-A-type small organic molecules with an enlarged linker system towards organic solar cells and the effect of co-adsorbents on cell performance. New J Chem 2016; 40:634-40. 
[84] Stalder R, Xie D, Islam A, Han L, Reynolds JR, Schanze KS. Panchromatic DonorAcceptor-Donor conjugated oligomers for dye-sensitized solar cell applications. ACS Appl Mater Interfaces 2014; 6:8715-22.

[85] Huang JH, Lee KC. Highly Stable, Solution-processable phenothiazine derivative as hole collection material for organic solar cells. ACS Appl Mater Interfaces 2014; 6:7680-5.

[86] Roquet S, Cravino A, Leriche P, Aleveque O, Frere P, Roncali J. Triphenylaminethienylenevinylene hybrid systems with internal charge transfer as donor materials for heterojunction solar cells. J Am Chem Soc 2006; 128: 3459-66.

[87] Bolisetty MNKP, Li CT, Thomas KRJ, Bodedla GB, Ho KC. Benzothiadiazole-based organic dyes with pyridine anchors for dye-sensitized solar cells: Effect of donor on optical properties. Tetrahedron 2015; 71, 4203-12.

[88] Zhong C, Gao J, Cui Y, Li T, Han L. Coumarin-bearing triarylamine sensitizers with high molar extinction coefficient for dye-sensitized solar cells. J. Power Sources $2015 ; 273: 831-8$.

[89] Lia J, Kong F, Wu G, Chen W, Guo F, Zhang B, et al. Di-n-alkylphosphinic acids as coadsorbents for metal-free organicdye-sensitized solar cells. Synth Met 2014; 197 : 188-93.

[90] Liu J, Sun X, Li Z, Jin B, Lai G, Li H, et al. New D- $\pi$-A system dye based on dithienosilole and carbazole: Synthesis, photo-electrochemical properties and dyesensitized solar cell performance. J Photochem Photobiol, A 2014; 294:54-61.

[91] Choi IT, You BS, Eom YK, Ju MJ, Choi WS, Kang SH, et al. Triarylamine-based dual-function coadsorbents with extended $\pi$-conjugation aryl linkers for organic dyesensitized solar cells. Org Electron 2014; 15:3316-26. 
[92] Li T, Gao J, Cui Y, Zhong C, Ye Q, Han L. Novel D- $\pi$-A carbazole sensitizers with 4phenyl-2-(thiophen-2-yl) thiazole as $\pi$-bridge for dye-sensitized solar cells. J Photochem Photobiol, A 2015; 303-304:91-8.

[93] Qian X, Gao HH, Zhu YZ, Lu L, Zheng JY. 6H-Indolo[2,3-b]quinoxaline-based organic dyes containing different electron-rich conjugated linkers for highly efficient dye-sensitized solar cells. J. Power Sources 2015; 280:573-80.

[94] Ho PY, Siu CH, Yu WH, Zhou P, Chen T, Ho CL, et al. Molecular engineering of starburst triarylamine donor with selenophene containing $\pi$-linker for dye-sensitized solar cells. J Mater Chem C 2016; 4:713-26.

[95] Gupta A, Armel V, Xiang W, Bilic A, Evans RA. New organic sensitizers using 4(cyanomethyl)benzoic acid as an acceptor group for dye-sensitized solar cell applications. Dyes Pigm 2015; 113:280-8.

[96] Kumar D, Thomas KRJ, Lee CP, Ho KC. Novel pyrenoimidazole-based organic dyes for dye-sensitized solar cells. Org Lett 2011; 13:2622-5.

[97] Wua F, Lee LTL, Liu J, Zhao S, Chen T, Wang M, et al. Novel organic dyes based on diarylmethylene-bridged triphenylamine for dye-sensitized solar cells. Synth Met $2015 ; 205: 70-7$.

[98] Gautam P, Misra R, Sharma GD. Dicyanoquinodimethane-substituted benzothiadiazole for efficient small-molecule solar cells. Phys Chem Chem Phys $2016 ; 18,7235-41$.

[99] Yen YS, Ni JS, Hung WI, Hsu CY, Chou HH, Lin JT. Naphtho[2,3-

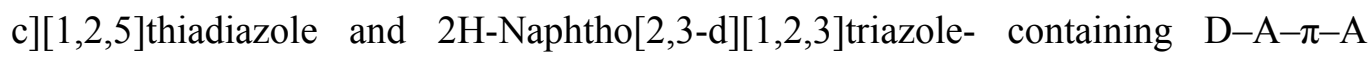
conjugated organic dyes for dye-sensitized solar cells, ACS Appl Mater Interfaces $2016 ; 8: 6117-26$. 
[100] Ooyama Y, Kanda M, EnoKi T, Adachi Y, Ohshita J. Synthesis, optical and electrochemical properties, and photovoltaic performance of a panchromatic and nearinfrared (D) $2-\pi-$ A type BODIPY dye with pyridyl group or cyanoacrylic acid, RSC Adv 2017; 7:13072-81.

[101] Yan C, Wu Y, Wang J, Li R, Cheng P, Bai H, Zhan Z, Ma W, Zhan X. Enhancing performance of non-fullerene organic solar cells via side chain engineering of fusedring electron acceptors, Dyes Pigm 2017; 139:627-34.

[102] Chen M, Yi M, Yi J, Li M, Du C, Lin K, Tong W, Ma C, Liu F, Wang H. Vinazene end-capped acceptor-donor-acceptor type small molecule for solution-processed organic solar cells, Org Electron 2017; 44:11-9.

[103] Qian X, Lan X, Yan R, He Y, Huang J, Hou L. T-shaped (D)2-A- - -A type sensitizers incorporating indoloquinoxaline and triphenylamine for organic dye-sensitized solar cells, Electrochim Acta 2017: DOI: 10.1016/j.electacta.2017.02.166.

[104] Zhao DX, Bian LY, Luo YX, Zhang MD, Cao H, Chen MD. Three-dimensional D- $\pi$ A organic sensitizer with coplanar triphenylamine moiety for dye-sensitized solar cells, Dyes Pigm 2017; 140:278-85.

[105] Dang D, Zhi Y, Wang X, Zhao B, Gao C, Meng L. A1-A-A type small molecules terminated with naphthalimide building blocks for efficient non-fullerene organic solar cells, Dyes Pigm 2017; 137:43-9.

[106] Ferreira E, Pascal LP, Cabon N, Caro B, Guen FRL, Pellegrin Y, Planchat A, Odobel F, New D- $\pi$-A-conjugated organic sensitizers based on $\alpha$-pyranylidene donors for dye-sensitized solar cells, Tetrahedron Lett 2017; 58:995-9.

[107] Zhao J, Li Y, Yang G, Jiang K, Lin H, Ade H, Ma W, Yan H. Efficient organic solar cells processed from hydrocarbon solvents, Nat. Energy 2016; 15027. 
[108] News release by Phillips 66 dated 12 $12^{\text {th }}$ June 2016, Web link: http://investor.phillips66.com/investors/news/news-release-details/2016/Phillips-66Sets-World-Record-in-Organic-Solar-Cell-Efficiency/default.aspx.

[109] Press release by Heliatek dated $8^{\text {th }}$ February 2016, Web link: http://www.heliatek.com/en/press/press-releases/details/heliatek-sets-new-organicphotovoltaic-world-record-efficiency-of-13-2. 